\title{
A MODEL FOR THE PREDICTION OF THE PUNCHING RESISTANCE OF STEEL FIBRE REINFORCED CONCRETE SLABS CENTRICALLY
}

\section{LOADED}

\author{
Bernardo N. Moraes Neto ${ }^{1}$, Joaquim A.O. Barros ${ }^{2}$, Guilherme S.S.A. Melo ${ }^{3}$
}

${ }^{1}$ University of Minho/University of Brasília-UnB, Dep. Civil Eng., School of Eng., Guimarães, Portugal, bnmn@hotmail.com.

${ }^{2}$ University of Minho, ISISE, Dep. Civil Eng., School of Eng., Campus de Azurém, Guimarães, Portugal, barros@civil.uminho.pt.

${ }^{3}$ University of Brasília-UnB, Dep. Civil Eng., Campus of Darcy Ribeiro, Brasília, Brasil, melog@unb.br.

\begin{abstract}
With the aim of contributing for the development of design guidelines capable of predicting with high accuracy the punching resistance of steel fibre reinforced concrete (SFRC) flat slabs, a proposal is presented in the present paper and its predictive performance is assessed by using a database that collects the experimental results from 154 punching tests. The theoretical fundaments of this proposal are based on the critical shear crack theory proposed by Muttoni and his co-authors. The proposal is capable of predicting the load versus rotation of the slab, and attends to the punching failure criterion of the slab. The proposal takes into account the recommendations of the most recent CEB-FIP Model Code for modelling the post-cracking behaviour of SFRC. By simulating the tests composing the collected database, the good predictive performance of the developed proposal is demonstrated.
\end{abstract}

Keywords: Reinforced concrete, Flat concrete slab, Punching, Steel fibre reinforced concrete, Analytical models.

\section{INTRODUCTION}


In recent years the use of steel fibres to increase of the punching resistance, and mainly, to convert brittle punching failure mode into ductile flexural failure mode of reinforced concrete (RC) flat slabs has been explored. In fact, available research [1-3] showed that, if proper mix compositions of steel fibre reinforced concrete (SFRC) are used, steel fibres can be suitable shear reinforcement for RC flat slabs, by improving the load carrying capacity and the energy absorption performance of the column-slab connection. These benefits are derived from the fibre reinforcement mechanisms provided by fibres bridging the micro-cracks that arrest the crack propagation, favouring the occurrence of large number of cracks of small width.

The resisting tensile stresses supported by the steel fibres in a cracked concrete have also the favourable effect of delaying the yield initiation of longitudinal and transversal conventional steel reinforcement, which contributes to increase the ultimate load carrying capacity of RC structures or to a partial suppression of conventional reinforcements.

By testing prototypes of real $[4,5]$ or smaller scale [6], the use of steel fibres has been investigated as, practically, the unique reinforcement of the flat slabs for residential and commercial buildings. This type of slabs, generally designated by Elevated Steel Fibre Reinforced Concrete (ESFRC) slabs, is reinforced with a steel fibre volume percentage, $V_{f}$, of about $1 \%$, and it includes a minimum continuity bars, also referred as anti-progressive collapse bars, placed in the bottom of the slab in the alignment of the columns [7]. In spite of the promising results obtained in these tests, reliable design models capable of predicting, with high accuracy, the load carrying capacity, the deformational response and the failure modes possible to occur in ESFRC slabs are not yet available, which is a considerable resistance for a comprehensive acceptation of this structural concept that apparently has several technical and economic advantages. Due to the brittle character of punching failure mode, the existence of a design model capable of predicting correctly the punching resistance and the deformation capacity of SFRC flat slabs is of paramount importance in this context. Some analytical models were proposed for the evaluation of the punching resistance of SFRC slabs, some of them with an eminent empirical nature, but the predictive performance of these models was, in general, limited to the simulation of a relatively small number of tests carried out by the authors [8-11]. In the present work a database collecting 154 punching tests with SFRC slabs was developed to appraise the predictive performance of these models and the one proposed by the authors of the present work. This model is based on the Critical Shear Crack Theory (CSCT) proposed by Muttoni [12], being possible to determine the 
punching resistance of SFRC slab by intersecting a curve corresponding to the load versus rotation $(V-\psi)$ of the column-slab connection, with a curve that defines the failure criterion. This model integrates the contribution of fibre reinforcement mechanisms using the recommendations of the most recent CEB-FIP Model Code 2010 [13]. The present paper describes the proposed formulation and compares its predictive performance using the aforementioned database.

\section{LOAD VERSUS ROTATION APPROACH}

\subsection{Refined formulation}

The load versus rotation proposed in the present work is based on the recommendations of Muttoni [12] that are applied to a column-slab connection assuming axisymmetric conditions for this structural component (Figure 1). The crack pattern of the slab at ultimate loading conditions can be assumed as divided into radial segments (Figure 1a). Each radial segment is delimited by a tangential crack formed close to the column, by two radial cracks, and by the edge considered as a free boarder of the slab.

According to some authors [14-16], it is admissible to assume that these radial segments rotate as free bodies in turn of the point localized at the bottom of the punching failure surface (Figure 1b). Therefore, it is accepted that a radial segment has constant rotation $\psi$ between the critical shear crack and its edge. According to Muttoni and Schwartz [17], in the column/slab connection the shear force $V$ is transmitted through a compression strut formed at the external region to the punching failure surface (Figure 1b). In Figure $1 \mathrm{~b}$ the variables $r_{c}, r_{0}, r_{q}$ and $r_{s}$ represent, respectively, the radius of column's cross section, the distance to the axis of the column of the punching failure surface $\left(r_{0}=r_{c}+d / 2\right.$, where $d$ is the internal arm of the longitudinal reinforcement), the distance of the circumferential loading line and the radius of the slab.

The stresses and the corresponding internal forces formed in the radial segment are indicated in Figure 2, where $F_{c r}$ and $F_{s r}$ represent the resultant force in the concrete in compression and in the reinforcement in tension, both in the radial direction, while $F_{c t}$ and $F_{s t}$ are the resultant force in the concrete in compression and in the reinforcement in tension, both in the tangential direction. The stress components $\sigma_{f, r}$ and $\sigma_{f, t}$ represent the post cracking tensile strength of SFRC in radial and tangential direction, respectively. Finally, $V$ and $V_{R}$ represent the acting and the resisting shear force, respectively. The force components $F_{c r}$ and $F_{s r}$, and the stresses $\sigma_{f, r}$ generate the radial bending moment $m_{r}$, while force components $F_{c t}$ and $F_{s t}$, and the 
stresses $\sigma_{f, t}$ produce the tangential bending moment $m_{t}$ (Figures $2 \mathrm{a}$ and $2 \mathrm{~b}$ ). For the evaluation of the $m_{r}$, the vertical component of the resisting force due to dowel effect provided by the longitudinal reinforcement was neglected, as well as the vertical component of the resultant stresses due to fibre reinforcement mechanisms. The representation shown in Figure 2c corresponds to a column/slab connection assumed in an axisymmetric conditions. When the slab has square geometry (Figure 3a), it can be converted into an equivalent circular slab (Figure 3b) by adopting the following transformations [18]:

$$
\begin{aligned}
& r_{c, e q}=\frac{2 \cdot e}{\pi} \\
& r_{q, e q}= \begin{cases}b_{q, c} & \text { for circular edge conditions } \\
b_{q, q} & \text { for rectangular edge conditions }\end{cases} \\
& r_{s, e q}=\frac{2}{\pi} \cdot[2 \cdot(\sqrt{2}-1) \cdot(L-e)+e]
\end{aligned}
$$

where $e$ is the edge of the cross section of the column, and $L$ is the edge of the slab, both assumed of square geometry.

According to Guandalini [19] and Muttoni [12], the load versus rotation of a slab in axisymmetric structural conditions can be directly obtained from the quadrilinear (4L) or bilinear (2L) moment-curvature diagram $(m-\chi)$ represented in Figure 4a. In this figure, the $m_{c r}$ and $m_{R}$ represents, respectively, the bending moment at crack initiation and the resisting bending moment (plastic bending moment) of the slab's cross section. The $E \cdot I_{0}$ and $E \cdot I_{I}$ represent the flexural stiffness of the slab's cross section before and after crack initiation, respectively. The $r_{c r}, r_{l}$ and $r_{y}$ is the distance from the axis of the column of the cross section where the curvature $\chi_{c r}, \chi_{I}$ and $\chi_{y}$ is installed, respectively. In these variables, the subscripts, $c r, 1$, and $y$ represent the crack initiation, the stabilization of the cracking process and the yield initiation of the longitudinal tensile reinforcement, respectively.

The equilibrium of bending moments in $O^{\prime}$ (Figure 2c) yields:

$$
\begin{aligned}
& \sum_{O^{\prime}} M=0 \\
& V(\psi) \cdot \frac{\left(r_{q}-r_{c}\right)}{2 \cdot \pi}=m_{r}(\psi) \cdot r_{0}+\int_{r_{0}}^{r_{s}} m_{t}(r) \cdot d r
\end{aligned}
$$


where $m_{t}$ is dependent of the distance $r$, which has justified the transformation of the $4 \mathrm{~L} m-\chi$ diagram (Figure 4a) into the $m-r$ diagram depicted in Figure $4 \mathrm{~b}$. Adopting the following assumption:

$$
\chi(\psi)=\frac{\psi}{r}
$$

the transformation of $m(\psi)$ into $m(r)$ is executed by performing a simple procedure of changing the variable:

$$
m(\psi)=\left\{\begin{array}{lll}
E \cdot I_{0} \cdot \chi(\psi) & \text { if } \quad \chi(\psi) \leq \chi_{c r} \\
m_{c r} & \text { if } \quad \chi_{c r}<\chi(\psi) \leq \chi_{1} \\
E \cdot I_{1} \cdot\left[\chi(\psi)+\chi_{t s}\right] & \text { if } \quad \chi_{1}<\chi(\psi) \leq \chi_{y} \\
m_{R} & \text { if } \quad \chi(\psi)>\chi_{y}
\end{array}\right.
$$

$m(r)=\left\{\begin{array}{lll}m_{R} & \text { if } & r_{0}<r \leq r_{y} \\ E \cdot I_{1} \cdot\left[\frac{\psi}{r}+\chi_{t s}\right] & \text { if } & r_{y}<r \leq r_{1} \\ m_{c r} & \text { if } & r_{1}<r \leq r_{c r} \\ E \cdot I_{0} \cdot \frac{\psi}{r} & \text { if } & r_{c r}<r \leq r_{s}\end{array}\right.$

Adopting the diagram of Figure $4 \mathrm{~b}$ and considering Eq. (8), the integral of Eq. (5) can be decomposed into:

$$
\int_{r_{0}}^{r_{s}} m_{t}(r) \cdot d r=\int_{r_{0}}^{r_{y}} m_{R} \cdot d r+\int_{r_{y}}^{r_{1}} E \cdot I_{1} \cdot \frac{\psi}{r} \cdot d r+\int_{r_{y}}^{r_{1}} E \cdot I_{1} \cdot \chi_{t s} \cdot d r+\int_{r_{1}}^{r_{c r}} m_{c r} \cdot d r+\int_{r_{c r}}^{r_{s}} E \cdot I_{0} \cdot \frac{\psi}{r} \cdot d r
$$

Introducing Eq. (9) into (5) and solving the integrals yields:

$$
V(\psi)=\frac{2 \cdot \pi}{\left(r_{q}-r_{c}\right)} \cdot\left[\begin{array}{l}
m_{r}(\psi) \cdot r_{0}+E \cdot I_{0} \cdot \psi \cdot\left\langle\ln \left(r_{s}\right)-\ln \left(r_{c r}(\psi)\right)\right\rangle+m_{c r} \cdot\left\langle r_{c r}(\psi)-r_{1}(\psi)\right\rangle+ \\
E \cdot I_{1} \cdot \psi \cdot\left\langle\ln \left(r_{1}(\psi)\right)-\ln \left(r_{y}(\psi)\right)\right\rangle+E \cdot I_{1} \cdot \chi_{t s} \cdot\left\langle r_{1}(\psi)-r_{y}(\psi)\right\rangle+ \\
m_{R} \cdot\left\langle r_{y}(\psi)-r_{0}\right\rangle
\end{array}\right]
$$

which is the equation that establishes the relationship between the rotation and the load carrying capacity of the slab. In this equation $m_{r}(\psi)$ is the radial bending moment for the rotation $\psi$, evaluated at $r=r_{0}$, and the mathematical operator $\langle x\rangle=x$ if $x \geq 0$ and $\langle x\rangle=0$ if $x<0$. To evaluate the plastic bending moment, $m_{R}$, the recommendations of CEB-FIP Model Code 2010 [13] for the simulation of the contribution of fibre reinforcement are adopted in the present work (Figure 5). A detailed description on the evaluation of $m_{R}$ is available elsewhere [18]. The bending moment at crack initiation, $m_{c r}$, is obtained from the following equation: 
$m_{c r}=\frac{f_{c t} \cdot h^{2}}{6}$

where $f_{c t}$ is the concrete tensile strength that can be estimated according to the recommendations of CEB-FIP Model Code 2010.

The $r_{c r}(\psi), r_{l}(\psi)$ and $r_{y}(\psi)$ in Eq. (10) is the position, from the axis of the column, of the section of the slab that develops the curvature $\chi_{c r}(\psi), \chi_{I}(\psi)$ and $\chi_{y}(\psi)$, respectively. These curvatures can be determined from the following relationships:

$$
\begin{array}{lll}
\chi_{c r}=\frac{m_{c r}}{E \cdot I_{0}} & \Rightarrow & r_{c r}(\psi)=\frac{\psi}{\chi_{c r}} \leq r_{s} \\
\chi_{1}=\frac{m_{c r}}{E \cdot I_{1}}-\chi_{t s} & \Rightarrow & r_{1}(\psi)=\frac{\psi}{\chi_{1}} \leq r_{s} \\
\chi_{y}=\frac{m_{R}}{E \cdot I_{1}}-\chi_{t s} & \Rightarrow & r_{y}(\psi)=\frac{\psi}{\chi_{y}} \leq r_{s}
\end{array}
$$

For the evaluation of the uncracked flexural stiffness, $E \cdot I_{0}$, the contribution of the reinforcement is neglected:

$$
E \cdot I_{0}=E \cdot \frac{h^{3}}{12}
$$

The evaluation of the flexural stiffness of SFRC cracked cross section, $E \cdot I_{l}$, was executed following the procedures adopted for RC members [18], and assuming a stabilized cracking phase:

$$
E \cdot I_{1}=\rho \cdot \beta \cdot E_{s} \cdot d^{3} \cdot\left(1-\frac{x}{d}\right) \cdot\left(1-\frac{x}{3 \cdot d}\right)
$$

The contribution of fibre reinforcement for the $E \cdot I_{I}$ is only indirectly taken in the evaluation of the neutral axis, $x$, Figure 5 ( $\eta$ and $\lambda$ parameters are evaluated according to [13], and $f_{F t u}$ is introduced in next section). In Eq. (16) $\beta$ is a factor intending to take into account the arrangement of the reinforcement, since the deduction of Eq. (10) was supported on the principle of axisymmetric structural conditions, but the majority of the built and tested RC flat slabs have orthogonal arrangement of the reinforcement [19]. According to Muttoni [12], $\beta=0.6$ yields to satisfactory results. The evaluation of the position of the neutral axis, $x$, was made according to the recommendations of CEB-FIP Model Code 2010 [13], see Figure 5. 
The $\chi_{t s}$ factor in Eq. (8) simulates the post-cracking tensile strength of cracked concrete (tension stiffening effect) that according to Muttoni [12] it can be determined from the following equation:

$$
\chi_{t s}=\frac{f_{c t}}{\rho \cdot \beta \cdot E_{s}} \cdot \frac{1}{6 \cdot h} \cong 0.5 \cdot \frac{m_{c r}}{E \cdot I_{1}}
$$

This means that the fibre reinforcement was not taken into account for the evaluation of $\chi_{t s}$. Enhancements in this respect can be adopted by using the closed form solution proposed by Taheri et al. [20] for determining the moment-curvature relationship of FRC of strain softening or strain hardening character, but this approach increases significantly the complexity of the model aimed to be proposed in the present work.

\subsection{Simplified formulation}

Instead of using the quadrilinear (4L) $m-\chi$ diagram to derive the load versus rotation relationship, in the present section the simpler bilinear (2L) $m-\chi$ diagram (or $m-r$ ) is adopted, since it provides a formulation more suitable for design purposes. To derive the load versus rotation relationship supported on the $2 \mathrm{~L} m-r$ diagram, it is necessary to assume the slab decomposed in two regions: elastic $\left(r_{y}<r_{0}\right)$ and elasto-plastic $\left(r_{0}<r_{y}<r_{s}\right)$, as represented in Figure 6b.

Establishing the bending moment equilibrium in $O^{\prime}$ point, and considering the elastic hypothesis $\left(r_{y}<r_{0}\right)$, it is obtained Eq. (5). In this equation:

$$
m_{r}(\psi) \cdot r_{0}=E \cdot I_{1} \cdot \frac{\psi}{r_{0}} \cdot r_{0}
$$

and

$$
\int_{r_{0}}^{r_{s}} m_{t}(r) \cdot d r=\int_{r_{0}}^{r_{s}} E \cdot I_{1} \cdot \frac{\psi}{r} \cdot d r=E \cdot I_{1} \cdot \psi \int_{r_{0}}^{r_{s}} \frac{d r}{r}=E \cdot I_{1} \cdot \psi \cdot[\ln (r)]_{r_{0}}^{r_{s}}=E \cdot I_{1} \cdot \psi \cdot \ln \left(\frac{r_{s}}{r_{0}}\right)
$$

Replacing Eqs. (18) and (19) into Eq. (5) it is obtained:

$$
V(\psi)=\frac{2 \cdot \pi}{\left(r_{q}-r_{c}\right)} \cdot E \cdot I_{1} \cdot \psi \cdot\left[1+\ln \left(\frac{r_{s}}{r_{0}}\right)\right] \text { for } r_{y} \leq r_{0}(\text { elastic regime })
$$

Analogously, for the elasto-plastic case, $r_{0}<r_{y} \leq r_{s}$, the following equilibrium equation is derived: 
$V(\psi) \cdot \frac{\left(r_{q}-r_{c}\right)}{2 \cdot \pi}=m_{R} \cdot r_{0}+\int_{r_{0}}^{r_{s}} m_{t}(r) \cdot d r$

where

$$
\int_{r_{0}}^{r_{s}} m_{t}(r) \cdot d r=\int_{r_{0}}^{r_{y}} m_{R} \cdot d r+\int_{r_{y}}^{r_{s}} E \cdot I_{1} \cdot \frac{\psi}{r} \cdot d r=m_{R} \cdot\left(r_{y}-r_{0}\right)+E \cdot I_{1} \cdot \psi \cdot \ln \left(\frac{r_{s}}{r_{y}}\right)
$$

Replacing Eq. (22) into Eq. (21) it is obtained:

$V(\psi)=\frac{2 \cdot \pi}{\left(r_{q}-r_{c}\right)} \cdot E \cdot I_{1} \cdot \psi \cdot\left[1+\ln \left(\frac{r_{s}}{r_{y}}\right)\right]$ for $r_{0}<r_{y}<r_{s}$ (elasto-plastic regime)

Based on experimental results $[3,21,22]$, it was verified that the slab's rotation is proportional to $\left(V / V_{f l e x}\right)^{3 / 2}$, where $V$ and $V_{f l e x}$ is, respectively, the actuating shear force and the load corresponding to the flexural failure of the slab:

$\psi \alpha\left(\frac{V}{V_{\text {flex }}}\right)^{3 / 2}$

To obtain $V_{\text {flex }}$ the equilibrium Eq. (21) is considered with:

$\int_{r_{0}}^{r_{s}} m_{R} \cdot d r=m_{R} \cdot\left(r_{s}-r_{0}\right)$

and assuming $r_{y}=r_{s}$, see Figure $6 \mathrm{~b}$, results:

$V_{\text {flex }}=2 \cdot \pi \cdot m_{R} \cdot \frac{r_{s}}{\left(r_{q}-r_{c}\right)} \quad$ for $r_{y}=r_{s}($ flexural failure load $)$

Combining Eqs. (23) and (26), and assuming $r_{y}=0.35 \cdot r_{s}$ that was determined from experimental evidence [18], the following relationship between load and rotation was derived [18]:

$\psi=0.5 \cdot \frac{m_{R} \cdot r_{S}}{E \cdot I_{1}} \cdot\left(\frac{V}{V_{\text {flex }}}\right)$

Eq. (24) can get the following configuration 
$\psi=\overline{\bar{\Delta}} \cdot\left(\frac{V}{V_{\text {flex }}}\right)^{3 / 2}$

where $\overline{\bar{\Delta}}$ is the constant relating $\psi$ and $\left(V / V_{f l e x}\right)^{3 / 2}$, whose value was determined by dimensional analysis [18]. In this analysis the same parameters of Eq. (27) were considered, $m_{R}, r_{s}, E \cdot I_{l}$, having resulted the following equation [18]:

$\psi=\bar{\Delta} \cdot \frac{m_{R} \cdot r_{s}}{E \cdot I_{1}} \cdot\left(\frac{V}{V_{\text {flex }}}\right)^{3 / 2}$

where $\bar{\Delta}=0.65$ for regular concrete and $\bar{\Delta}=1.625$ for concrete of lightweight aggregates. For slabs in axisymmetric structural conditions, $V_{\text {flex }}$ is obtained from Eq. (26), while for square slabs the yield line theory leads to: $V_{f l e x}=8 \cdot m_{R}$. Eq. (29) is the simplified expression for the load versus rotation that is recommended to be used in the design practice.

If the contribution of the reinforcement in compression is neglected, and concrete crushing is assumed to occur simultaneously with the yield of the longitudinal reinforcement, Eq. (29) gets the following configuration, whose deduction is described in detail elsewhere [18]:

$\psi=\bar{\Delta} \cdot \frac{r_{s}}{d \cdot E_{s}} \cdot\left\{4 \cdot f_{s y}+\frac{f_{F t u}\left(w_{u}\right) \cdot\left[1+4 \cdot\left(c^{\prime} / d\right)\right]}{\rho}\right\} \cdot\left(\frac{V}{V_{\text {flex }}}\right)^{3 / 2}$

where

$$
\begin{aligned}
& f_{F t u}\left(w_{u}\right)=f_{F t s}-\frac{w_{u}}{2.5} \cdot\left(f_{F t s}-0.5 \cdot f_{R 3}+0.2 \cdot f_{R 1}\right) \geq 0 ; f_{F t s}=0.45 \cdot f_{R 1} \\
& f_{R 1}=7.5 \cdot\left(V_{f} \cdot \frac{l_{f}}{d_{f}}\right)^{0.8} \\
& f_{R 3}=6.0 \cdot\left(V_{f} \cdot \frac{l_{f}}{d_{f}}\right)^{0.7}
\end{aligned}
$$

In Eq. (30) $\bar{\Delta}=0.358$ for regular concrete and $\bar{\Delta}=0.894$ for concrete of lightweight aggregates, and $\rho, f_{s y}$ and $E_{s}$ represents, respectively, the reinforcement ratio, the yield stress and the modulus of elasticity of the 
flexural reinforcement. The parameter $c^{\prime}$ in Eq. (30) is the distance of the flexural reinforcement to the concrete tensile surface $(\Delta \cdot d$ in Figure 5).

In Eqs. (30) and (31), $f_{F t u}\left(w_{u}\right)$ is the post-cracking residual strength of $S F R C$ at ultimate limit conditions, where $w_{u}$ is the maximum acceptable crack width imposed by design conditions. According to the CEB-FIP Model Code 2010 [13], $f_{F t u}\left(w_{u}\right)$ should be evaluated for $w_{u}=1.5 \mathrm{~mm}$. In Eq. (31) $f_{R I}$ and $f_{R 3}$ are the residual flexural tensile strength parameters, whose evaluation is carried out according to the recommendations of CEB-FIP Model Code 2010, by performing three point notched beam bending tests [13]. In Eqs. (32) and (33) $V_{f}$ and $l_{f} / d_{f}$ and the fibre volume percentage and fibre aspect ratio (quotient between fibre length, $l_{f}$, and fibre diameter, $d_{f}$ ).

\subsection{Prediction of the residual flexural tensile strength parameters of SFRC by using a database}

As already mentioned, the predictive performance of the proposed models will be assessed by comparing the estimated results with those available in a database (DB) that collects 154 punching tests. In these models, the contribution of fibre reinforcement is simulated by using the concept of residual flexural tensile strength parameters, $f_{R i}$, whose values, in the majority of the works composing the $\mathrm{DB}$, are not available. Therefore, to apply the proposed models to the tests composing the $\mathrm{DB}$, another database was built by collecting results $\left(f_{R i}\right)$ of the characterization of the post-cracking flexural behaviour of SFRC according to the recommendations of CEB-FIP Model Code 2010. Since the fibre volume percentage, $V_{f}$, and fibre aspect ratio, $l_{f} d_{f}$, are practically the unique common information available in the works forming the DB of the punching tests, the statistical analysis performed with the collected data for the characterization of the postcracking behaviour of SFRC was governed by the criterion of deriving equations for the $f_{R i}$ dependent on the $V_{f}$ and $l_{f} / d_{f}$. The authors are aware that this is a quite simple approach to simulate the fibre reinforcement mechanisms, since other variables like the fibre-matrix bond strength, fibre inclination and fibre embedment length influence the values of $f_{R i}$, but this information is not available in those works. Therefore, a relatively large scatter of results is naturally expected for the relationships $f_{R i}-\left(V_{f}, l_{f} d_{f}\right)$, but actually this is the unique possibility of considering the fibre reinforcement mechanisms according to the CEB-FIP Model Code 2010 for the prediction of the punching failure load of the slabs collected in the DB by applying the proposed 
models. The authors are doing an effort to increase this database and, therefore, deriving more reliable $f_{R i}-$ $\left(V_{f}, l_{f} d_{f}\right)$ relationships. Eqs. (32) and (33) were obtained according to the described methodology [18].

In a design context of a SFRSC slab, three point notched SFRSC beam bending tests should be executed according to the recommendations of CEB-FIP Model Code 2010 in order to obtain the $f_{R i}$ of the SFRSC, and these values should be directly used in the proposed model for the evaluation of the punching failure load of a SFRSC slab supported on columns.

\section{FAILURE CRITERION}

\subsection{Fundamental formulation}

In the present approach it is assumed that the punching resistance of a RC slab can be estimated according to the critical section concept, e.g., the nominal shear stress, $v_{R}$, is defined as the ratio between the punching failure load $\left(V_{u}\right)$ and an area considered as representative of the punching failure surface $\left(b_{0} \cdot d\right)$ :

$$
v_{R}=\frac{V_{u}}{b_{0} \cdot d}
$$

where $b_{0}$ represents the punching critical perimeter at a distance $\alpha \cdot d$ from the external surface of the column

(Figure 7). It is also assumed that the contribution of fibre reinforcement can be integrated in Eq. (34) by using a $k_{f}$ factor:

$v_{R}=\frac{V_{u}}{b_{0} \cdot d} \cdot \frac{1}{k_{f}^{a_{1}}}$

where this factor simulates the influence of the most important steel fibre reinforcement mechanism, namely: fibre volume percentage $\left(V_{f}\right)$, fibre aspect ratio $\left(l_{f} / d_{f}\right)$ and fibre-matrix bond strength $\left(\tau_{b}\right)$. The $a_{l}$ factor aims to simulate the degree of influence of these fibre characteristics on the punching resistance of $S F R C$ slab. In order to integrate these new aspects in the Critical Shear Crack Theory (CSCT) proposed by Muttoni [12], the $k_{f}{ }^{a_{1}}$ was included in the equation of the CSCT, resulting:

$\frac{V_{u}}{b_{0} \cdot d \cdot k_{f} a_{1}}=v_{c} \cdot f\left(w, d_{0}\right)$ 
where $f\left(w, d_{0}\right)$ is a function dependent on crack width, $w$, and on the roughness of the punching failure surface that was assumed correlated to the diameter of the aggregates, $d_{0}$. If the proposal of Muttoni and Schwartz [17] for the determination of $w$ from the rotation of the slab $(\psi \cdot d)$ is now considered, yields:

$\frac{V_{u}}{b_{0} \cdot d \cdot k_{f} a_{1}}=\frac{v_{c}}{a_{2}+a_{3} \cdot \psi \cdot d}$

According to Muttoni [12], and in agreement with the results from Walraven [24], and Vecchio and Collins [25], the contribution of the aggregate interlock for the concrete shear resistance can be estimated by multiplying $\psi \cdot d$ by $k_{d g}$, where $k_{d g}=1 /\left(d_{g 0}+d_{g}\right)$, being $d_{g 0}=16 \mathrm{~mm}$ the reference diameter, and $d_{g}$ the maximum diameter of the aggregates. In concrete of lightweight aggregates it is assumed $d_{g}=0$, since the fracture progresses through the aggregates resulting a relatively smooth surface. Therefore, the following equation governs the punching failure criterion of SFRC slabs:

$\frac{V_{u}}{b_{0} \cdot d \cdot k_{f} a_{1}}=\frac{v_{c}}{a_{2}+a_{3} \cdot \psi \cdot d \cdot k_{d g}}$

being $v_{c}$ the concrete nominal shear strength [26], which will be determined in the next section, as well as the $a_{i}(i=1$ to 3$)$ and $k_{f}$ parameters.

\subsection{Proposal}

The values of $a_{i}$ parameters that define Eq. (38) were determined by fitting as much as possible the $V_{u^{-}} \psi$ response recorded in experimental punching tests with RC slabs. According to ACI 318 [26], the parameter $b_{0}$, which defines the perimeter of the punching failure surface, is localized at a distance $d / 2$ from the external surface of the column. This parameter and $v_{c}$ are obtained from the following equations:

$$
\begin{aligned}
& b_{0}=4 \cdot e+\pi \cdot d \quad \text { (for column of square cross section) } \\
& v_{c}=0.33 \cdot \sqrt{f_{c}}
\end{aligned}
$$

being $e$ the edge of the column's cross section. For the reasons indicated at the end of the previous chapter, the $k_{f}$ factor was assumed dependent on the $V_{f}$ and $l_{f} / d_{f}$ fibre parameters: 


$$
k_{f}=V_{f} \cdot \frac{l_{f}}{d_{f}}
$$

To determine the $a_{i}$ parameters, the value of $a_{l}$ was varied between 0 and 1 with small increments of $a_{l}$, and for each $a_{1}$, the values of $a_{2}$ and $a_{3}$ that best fit the experimental results (smallest $R^{2}$ ) were obtained. A preliminary parametric study in this context has indicated that values of $a_{l}$ outside of the aforementioned interval conduct to worst predictions of the experimental results. The following optimized $a_{i}$ parameters were those corresponding to the smallest $R^{2}$ of the performed analysis: $a_{1}=1 / 3, a_{2}=1.33, a_{3}=1.82$. Replacing these values in Eq. (38) results:

$\frac{V_{u}}{b_{0} \cdot d \cdot \sqrt{f_{c}} \cdot\left(V_{f} \cdot \frac{l_{f}}{d_{f}}\right)^{1 / 3}}=\frac{1}{1.33+1.82 \cdot \psi \cdot d \cdot k_{d g}}$

\subsection{Assessment of the predictive performance of the proposal}

In this section the predictive performance of equation (42), as representative of the punching failure criterion of $S F R C$ flat slabs, is assessed. For this purpose, the $\lambda=v_{\text {exp }} / v_{\text {the }}$ parameter, comparing the experimental ( $\left.v_{\text {exp }}\right)$ and the theoretical $\left(v_{t h e}\right)$ values, is determined. The values of $\lambda$ are evaluated according to a modified version of the Demerit Points Classification (DPC) proposed by Collins [27], where a penalty (PEN) is assigned to each range of $\lambda$ parameter according to Table 1 , and the total of penalties determines the performance of the proposal. The theoretical results were obtained from the following equation:

$$
v_{\text {the }}=\frac{1}{1.33+1.82 \cdot \psi \cdot d \cdot k_{d g}}
$$

while the experimental results were determined from the following equation:

$$
v_{\text {exp }}=\frac{V_{u}}{b_{0} \cdot d \cdot \sqrt{f_{c}} \cdot\left(V_{f} \cdot \frac{l_{f}}{d_{f}}\right)^{1 / 3}}
$$

Figure $8 \mathrm{a}$ shows the predictive performance of the proposal, while Figures $8 \mathrm{~b}$ and $8 \mathrm{c}$ present the safe $(\lambda \geq 1)$ and unsafe $(\lambda<1)$ results (in percentage) and a "box and whiskers" plot of the $\lambda$ parameter, respectively. The box plot diagram graphically depicts the statistical five-number summary, consisting of the minimum and 
maximum values, and the lower $(\mathrm{Q} 1)$, median $(\mathrm{Q} 2)$ and upper $(\mathrm{Q} 3)$ quartiles. The obtained results are included in Table 2, where the number of samples, the penalty for each range of $\lambda$ parameter, and the total of penalties (Total PEN) are indicated, as well as the average (AVG), the standard deviation (STD) and the coefficient of variation (COV). The number of samples was limited to 40 because, in the majority of the slabs composing the DB the ultimate deflection was not provided, whose value if fundamental for the evaluation of the ultimate rotation of the slab to be introduced in Eq. (42). Figure 8 shows that $R^{2}$ of the $v_{\exp }{ }^{-}$ $v_{\text {the }}$ is quite small. However, Table 2 reveals that the average of $\lambda$ is close to the unit value, and its COV is relatively low. Therefore, the assumptions subjacent to this proposal for representing the punching failure criterion of SFRC flat slabs are acceptable:

$$
\frac{V_{u}}{b_{0} \cdot d \cdot \sqrt{f_{c}} \cdot k_{f}^{1 / 3}}=\frac{1}{1.33+1.82 \cdot \psi \cdot d \cdot k_{d g}} \quad\left\{\begin{array}{l}
b_{0}=4 \cdot e+\pi \cdot d(\text { for column of square cross section }) \\
k_{f}=V_{f} \cdot \frac{l_{f}}{d_{f}} \\
k_{d g}=\frac{1}{d_{g 0}+d_{g}}
\end{array}\right.
$$

This equation, in spite of describing satisfactorily the punching failure criterion for $S F R C$ flat slabs, has the inconvenient of do not being generalized for the cases of plain concrete $\left(V_{f}=0\right)$. To overcome this deficiency, the parameters $\lambda_{f}$ and $\mu_{f}$ are introduced into Eq. (45) resulting:

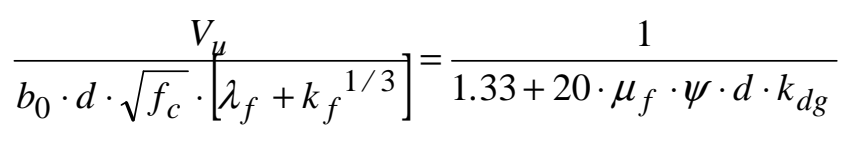

where

$$
\begin{aligned}
& \lambda_{f}=\left\{\begin{array}{l}
0 \text { if } V_{f} \neq 0 \\
1 \text { if } V_{f}=0
\end{array}\right. \\
& \mu_{f}=\left\{\begin{array}{l}
1 / 11 \text { if } V_{f} \neq 0 \\
1 \quad \text { if } V_{f}=0
\end{array}\right.
\end{aligned}
$$

When $V_{f}=0$, Eq. (46) becomes the one proposed by Muttoni [12] for RC slabs:

$$
\frac{V_{u}}{b_{0} \cdot d \cdot \sqrt{f_{c}}}=\frac{1}{1.33+20 \cdot \psi \cdot d \cdot k_{d g}}=\frac{3 / 4}{1+15 \cdot \psi \cdot d \cdot k_{d g}}
$$


Taking experimental results found in the bibliography, Figure 9 evidences that Eq. (46) assures a satisfactory predictive performance for the punching failure criterion. In this figure the $v$ symbol of the ordinate axis represents the left term of Eq. (46).

\section{APPRAISAL OF THE PREDICTIVE PERFORMANCE OF THE PROPOSALS}

\subsection{Database (DB)}

A database (DB) composed by 154 slabs submitted to punching test configuration was built, 137 of them were reinforced with longitudinal steel bars/grids in order to avoid the occurrence of flexural failure mode. None of these slabs has conventional shear/punching reinforcement. However, 105 slabs composing the DB were made by SFRC. In terms of concrete average compressive strength, $f_{c m}$, the DB is composed of slabs with $f_{c m}$ in the range of 14 to $93 \mathrm{MPa}$, so a quite high interval exists for a parameter that has a relevant impact on the punching resistance of concrete slabs. For the slabs that were flexurally reinforced with steel bars, the internal arm of this reinforcement ( $d$, Figure 1) has varied from $13 \mathrm{~mm}$ to $180 \mathrm{~mm}$, while the reinforcement ratio $(\rho)$ is in the interval 0.4 to $2.75 \%$. In the SFRC slabs, "hooked", "twisted", "crimped", "corrugated", "paddle" and "Japanese" type of fibres were used, with an aspect-ratio that varied from 20 to 100, and in a volume percentage $\leq 2 \%$. In some of the SFRC slabs (6 specimens), the SFRC was only applied in a region around the loaded area (that represents the position of the column), considered the region where punching failure could occur. In terms of loading conditions, all the slabs of the DB were submitted to a load distributed in a certain area of the slab without transferring any bending moments from the loading device to the slab. In the tests of the DB, the columns were simulated by a RC element monolithically connected to the slab, or applying steel plates, or even introducing a semi-spherical device in between the piston of the actuator and the tested slab. The cross section of the columns and steel plates was square or circular. To avoid results that can compromise the reliability of this statistical analysis, the slabs with a thickness lower than $80 \mathrm{~mm}$ were discarded, since an eventual influence of size effect can have a detrimental consequence on this study. Furthermore, the slabs where the concrete compressive strength has decreased more than $15 \%$ in consequence of the addition of fibres were also neglected, since this decrease reveals that the SFRC mix composition was not properly designed. 


\subsection{General statistical analysis procedures}

The performance of the proposals for the prediction of the punching resistance of SFRC slabs is appraised using the collected data registered in the DB. For each proposal, the obtained values of $V_{\text {the }}$ are compared with $V_{\text {exp }}$, and a $\lambda$ factor corresponding to the $V_{\text {exp }} / V_{\text {the }}$ ratio is evaluated. The values of $\lambda$ were classified according to the modified version of the DPC (Table 1).

\subsection{Results}

The performance of the proposals corresponding to Eqs. (10), (29) and (30) for the prediction of the load versus rotation, with Eq. (46) that represents the failure criterion, is presented in Figure 10, where experimental and theoretical results are compared. In this figure and in the following analyses, the proposal corresponding to Eq. (10), (29) and (30) is designated as Refined, Simple and Balanced, respectively. The $v$ symbol of the ordinate axis represents the left term of Eq. (46). Figure 10 shows that the three approaches have satisfactory predictive performance in terms of load versus rotation, and when conjugated with the proposed failure criteria can estimate with good accuracy the punching failure load. The performance of the three proposals for the prediction of the punching failure load of the slabs composing the DB is assessed in Figures $11 \mathrm{a}, 11 \mathrm{~b}$ and $11 \mathrm{c}$, by comparing $V_{\text {exp }}$ and $V_{\text {the. }}$. Figure $11 \mathrm{~d}$ shows the minimum and maximum values, and the lower $(\mathrm{Q} 1)$, median $(\mathrm{Q} 2)$ and upper $(\mathrm{Q} 3)$ quartiles of the $\lambda=V_{\text {exp }} / V_{\text {the }}$ values predicted by the three proposals. Table 3 includes the analysis of $\lambda$ according to the modified version of DPC (see also Table 1). Figure 11 and Table 3 reveal that the proposals corresponding to Eqs. (10), (29) and (30) with the failure criteria represented by Eq. (46) predict with good accuracy the results registered experimentally, with a relatively small dispersion of results (the COV varied between $12 \%$ and $13 \%$ ), being the Refined model the one that conducts to the higher $R^{2}$, smallest number of total penalties, and largest number of samples with proper safety margin.

\section{COMPARISON TO THE PREDICTIVE PERFORMANCE OF OTHER MODELS}


In this section the predictive performance of the developed model is compared to the one of the formulations proposed by: Narayanan and Darwish [8], Shaaban and Gesund [29], Harajli et al. [9], Holanda [22], Choi et al. [30], Muttoni and Ruiz [10] and Higashiyama et al. [31]. A detailed description of these formulations can be found elsewhere [32], but a resume is in the appendix. Like in the previous sections, the predictive performance is appraised in terms of the $\lambda=V_{\text {exp }} / V_{\text {the }}$ factor and considering the modified version of $D P C$ (Table 1). The obtained results are indicated in Table 4 and represented in Figure 12. Each of the models in comparison is designated by MODi ( $\mathrm{i}=1$ to 7 ) and its corresponding reference is indicated in the footnote of Table 4 and in the caption of Figure 12. From the obtained results it can be concluded that the model proposed in the present work, regardless of the three levels sophistication, together with the model of Muttoni and Ruiz [10], are those that assure the highest performance for the prediction of the punching failure load of SFRC flat slabs. In terms of the modified version of DPC, Table 4 shows that the proposed Refined model provides the lowest total penalties, with the highest number of predictions of $\lambda$ in the intervals [0.85-1.15[ and [1.15-2.0] $(37+11)$, to which correspond the lowest penalty values, being consequently the more reliable model.

\section{CONCLUSIONS}

In the present work three proposals were described for the prediction of the punching failure of steel fibre reinforced concrete (SFRC) flat slabs submitted to centrically loading conditions. The proposals are based on the critical shear crack theory, and only diverge on the level of sophistication adopted to define the load versus rotation for the slabs. The punching failure criterion adopted in these proposals is based on the experimental results collected in a database and on the recommendations of ACI 318. The database is composed of 154 experimental punching tests with flat slabs. This database was also used to appraise the predictive performance of developed proposals, by performing a statistical analysis of the $\lambda=V_{\text {exp }} / V_{\text {the }}$, where $V_{\text {exp }}$ and $V_{\text {the }}$ is the punching failure load registered experimentally and predicted analytically, respectively. The predictive performance of the model was also assessed by applying a modified version of the Demerit Points Classification. All the three versions of the proposal predict satisfactorily the load versus rotation of the slabs of the database, and estimates $\lambda$ values in the interval 1.0 to 1.04 with a coefficient of variation less 
than $13 \%$, which is relatively small considering the complexity of the punching phenomenon. By comparing the performance of the developed proposal to the another seven models for the prediction of the $V_{\text {exp }}$, it was also verified that the more refined version of the proposed model assured the highest predictive performance with the largest number of predictions in the intervals considered proper for safety design.

\section{ACKNOWLEDGEMENTS}

The study presented in this paper is a part of the research project titled "SlabSys-HFRC - Flat slabs for multistorey buildings using hybrid reinforced self-compacting concrete: an innovative structural system", with reference number of PTDC/ECM/120394/2010. The first author acknowledges the support provided by the CAPES and CNPq grant, and the grant provided by the project SlabSys.

\section{REFERENCES}

[1] Tan, K-H.; Paramasivam, P. Punching shear strength of steel fiber reinforced concrete slabs. Journal of Materials in Civil Engineering, 6(2), 240-253, May 1994.

[2] Prisco, M.; Felicetti, R. Some results on punching shear in plain and fibre-reinforced micro-concrete slabs. Magazine of Concrete Research, 49(180), 201-219, September 1997.

[3] Nguyen-Minh, L.; Rovňák M.; Tran-quoc T.; Nguyen-Kim, K. Punching shear resistance of steel fiber reinforced concrete flat slabs, "Punching shear resistance of steel fiber reinforced concrete flat slabs", Proceedings of The Twelfth East Asia-Pacific Conference on Structural Engineering and Construction (EASEC-12), Hong Kong Special Administrative Region, China, 535-536 (with CD-rom), 24-26th January 2011.

[4] Destrée, X., Free suspended elevated slabs of steel fibre reinforced concrete: full scale test results and design, 7th International Symposium of Fiber-Reinforced Concrete: Design and Applications BEFIB 2008, Editor: R. Gettu, pp. 941-950, Sept. 2008.

[5] Destrée, X.; Mandl, J. Steel fibre only reinforced concrete in free suspended elevated slabs: Case studies, design assisted by testing route, comparison to the latest SFRC standard documents. Tailor Made Concrete Structures - Walraven \& Stoelhorst (eds), Taylor \& Francis Group, 437-443, London 2008. 
[6] Barros, J.A.O.; Salehian, H.; Pires, N.M.M.A; Gonçalves, D.M.F. Design and testing elevated steel fibre reinforced self-compacting concrete slabs. BEFIB2012-Fibre reinforced concrete, 2012.

[7] Sasani, M.; Sagiroglu, S. Progressive collapse of reinforced concrete structures: a multihazard perspective. ACI Structural Journal, 105(1), 96-105, January/February 2008.

[8] Narayanan, R., Darwish, I.Y.S. Punching Shear Tests on Steel Fibre Reinforced Microconcrete Slabs. Magazine of Concrete Research, 39(138), 42-50, 1987.

[9] Harajli, M.H.; Maalouf D.; Khatib H. Effect of fibers on the punching shear strength of slab-column connections. Cement \& Concrete Composites, 17(2), 161-170, 1995.

[10] Muttoni, A.; Ruiz, M.F. The critical shear crack theory as mechanical model for punching shear design and its application to code provisions. Fédération Internationale du Béton, Bulletin 57, Lausanne, Switzerland, 31-60, 2010.

[11] Michels, J.; Waldmann, D.; Maas, S.; Zürbes, A. Steel fibers as only reinforcement for flat slab construction - Experimental investigation and design. Construction and Building Materials, 26, 145-155, 2012.

[12] Muttoni, A. Punching shear strength of reinforced concrete slabs without transverse reinforcement. ACI Structural Journal, 105(4), 440-450, July/August 2008.

[13] CEB-FIP. Model Code 2010: Final Draft. Model Code prepared by Special Activity Group 5, Lausanne, September 2011.

[14] Kinnunen, S.; Nylander, H. Punching of Concrete Slabs without Shear Reinforcement, Transactions of the Royal Institute of Technology, 158, Stockholm, Sweden, 112 pgs, 1960.

[15] Shehata, I. A. E. M. Punching of prestressed and non-prestressed reinforced concrete flat slabs. PhD Thesis - The Polytechnic of Central London, London, 1985.

[16] Alexander, S.D.B.; Simmonds, S.H. Bond model for strength of slab-column joints. Department of Civil Engineering, Structural Engineering Report n 174, University of Alberta, 1991.

[17] Muttoni, A.; Schwartz, J. Behaviour of Beams and Punching in Slabs without Shear Reinforcement. IABSE Colloquium, 62, 703-708, Zurich, Switzerland, 1991. 
[18] Moraes Neto, B.N. Punching behaviour of steel fibre reinforced concrete slabs submitted to symmetric loading. PhD in Civil Engineering, Department of Civil and Environmental Engineering, University of Brasília, Brasília, DF, January, 2013. (in Portuguese)

[19] Guandalini, S. Poinçonnement symétrique des dalles en béton armé. PhD Thesis 3380, Ecole Polytechnique Fédérale de Lausanne, Switzerland, 2005. (in French)

[20] Taheri, M.; Barros, J.A.O.; Salehian, H.R., “A parametric study on the use of strain softening/hardening FRC for RC elements failing in bending”, ASCE Materials in Civil Engineering Journal, 24(3), 259-274, 2012.

[21] Azevedo, A.P., "Resistance and ductility of column-slab connections in slabs of high strength steel fibre reinforced concrete and including steel studs", MSc Thesis. EESC-USP, Brazil, 1999. (in Portuguese)

[22] Holanda, K.M.A., "Analysis of resistant mechanisms and similarities of the adition effect of steel fibers on strength and ductility to both punching shear of flat and the shear of concrete beams", PhD Thesis. São Carlos, Brazil, 2002. (in Portuguese)

[23] Cunha, V.M.C.F.; Barros, J.A.O.; Sena-Cruz, J.M., "Pullout behaviour of steel fibres in self-compacting concrete”, ASCE Materials in Civil Engineering Journal, 22(1), 1-9, January 2010.

[24] Walraven, J.C. Fundamental Analysis of Aggregate Interlock. Journal of Structural Engineering, ASCE, 107(11), 2245-2270, 1981.

[25] Vecchio, F.J.; Collins, M.P. The Modified Compression-Field Theory for Reinforced Concrete Elements Subjected to Shear. ACI JOURNAL, Proceedings 83(2), 219-231, 1986.

[26] ACI 318. Building Code Requirements for Structural Concrete, American Concrete Institute, Farmington Hills, Michigan, 2008.

[27] Collins, M.P. Evaluation of shear design procedures for concrete structures. A Report prepared for the CSA technical committee on reinforced concrete design, 2001.

[28] Alexander, S.; Simmonds, S. Punching shear tests of concrete slabs-column joints containing fiber reinforcement. ACI Structural Journal, 89(4), 425-332, Jul/Aug 1992.

[29] Shaaban, A.M.; Gesund, H. Punching shear strength of steel fiber reinforced concrete flat plates. ACI Structural Journal, 91(4), 406-414, Jul/Aug 1994. 
[30] Choi, K-K.; Taha, M.M.R.; Park, H-G.; Maji, A.K. Punching shear strength of interior concrete slabcolumn connections reinforced with steel fibers. Cement \& Concrete Composites, 29, 409-420, 2007.

[31] Higashiyama, H.; OTA, A.; Mizukoshi, M. Design equation for punching shear capacity of SFRC slabs. International Journal of Concrete Structures and Materials, 5(1), 35-42, 2011.

[32] Moraes-Neto, B.N.; Barros, J.A.O.; Melo, G.S.S.A. The predictive performance of design models for the punching resistance of SFRC slabs in inner column loading conditions. $8^{\text {th }}$ RILEM International symposium on fibre reinforced concrete: challenges and opportunities (BEFIB 2012), September, 2012.

[33] Cheng, M-Y.; Parra-Montesinos, G.J. Evaluation of steel fiber reinforcement for punching shear resistance in slab-column connections - Part I: Monotonically increased load. ACI Structural Journal, 107(1), 101-109, Jan/Feb 2010.

[34] Mcharg, P. J. Effect of fibre-reinforced concrete on the performance of slab-column specimens. Montreal-Canada. Master thesis. McGill University, 1997.

[35] Theodorakopoulos, D.D.; Swamy, N. Contribution of steel fibers to the strength characteristics of lightweight concrete slab-column connections falling in punching shear. ACI Structural Journal. 90(4), 342355, Jul/Aug 1993.

[36] Özden, S.; Ersoy, U.; Ozturan, T. Punching shear tests of normal- and high-strength concrete flat plates. Can. J. Civ. Eng., 33, 1389-1400, 2006. 


\section{NOTATION}

$A_{\text {'s }} \quad$ Area of compression reinforcement

$A_{s} \quad$ Area of tension reinforcement

$b \quad$ Width of a isolated slab element

$b_{0} \quad$ Critical perimeter for punching shear

$b_{q, c} \quad$ Loaded line for square slabs in circular edge conditions

$b_{q, q} \quad$ Loaded line for square slabs in rectangular edge conditions

$c^{\prime} \quad$ Distance of the flexural reinforcement to the concrete tensile surface

$d \quad$ Internal arm of the slab

$d_{0} \quad$ Diameter of the aggregates

$d_{f} \quad$ Diameter of fibre

$d_{g} \quad$ Maximum diameter of the

$d_{g 0} \quad$ Reference diameter of the aggregates

$e \quad$ Edge of the column's cross section

E Modulus of elasticity of concrete

$E_{s} \quad$ Modulus of elasticity of reinforcement

$F$ 's Internal compressive force of compressive reinforcement

$f_{c} \quad$ Average compressive strength of concrete in cylinder specimens

$F_{c r} \quad$ Internal compressive force of concrete in radial direction

$F_{c t} \quad$ Internal compressive force of concrete in tangential direction

$f_{c t} \quad$ Average tensile strength of concrete (Brazilian test)

$f_{F t s} \quad$ Post-cracking strength for serviceability crack opening

$f_{F t u} \quad$ Post-cracking strength for ultimate crack opening

$f_{R i} \quad$ Residual flexural tensile strength of fibre reinforced concrete corresponding to CMOD $_{\mathrm{i}}$

$F_{s} \quad$ Internal compressive force of tensile reinforcement

$F_{s r} \quad$ Internal tensile force of reinforcement in radial direction

$F_{s t} \quad$ Internal tensile force of reinforcement in tangential direction

$f_{s y} \quad$ Yield strength of reinforcement

$h \quad$ Slab thickness

$I_{0} \quad$ Second moment of area of uncracked concrete cross-section

$I_{l} \quad$ Second moment of area of cracked concrete cross-section

$L \quad$ Span of slab

$l_{f} \quad$ Length of fibre

$m_{c r} \quad$ Bending moment at crack initiation

$m_{r} \quad$ Radial moment per unit width

$m_{R} \quad$ Resisting bending moment (plastic bending moment)

$m_{t} \quad$ Tangential moment per unit width

$r \quad$ Radial orientation

$r_{0} \quad$ Radius of the critical shear crack

$r_{l} \quad$ Radius of the zone in which cracking is stabilized

$r_{c} \quad$ Radius of a circular column

$r_{c, e q} \quad$ Radius of a circular column in an equivalent slab of circular geometry

$r_{c r} \quad$ Radius of cracked zone

$r_{q} \quad$ Radius of the load introduction at the perimeter

$r_{q, e q} \quad$ Radius of the load introduction at the perimeter in an equivalent slab of circular geometry

$r_{s} \quad$ Radius of circular isolated slab element

$r_{s, e q} \quad$ Radius of circular isolated slab element in an equivalent slab of circular geometry

$r_{y} \quad$ Radius of yielded zone

$t \quad$ Tangential orientation 


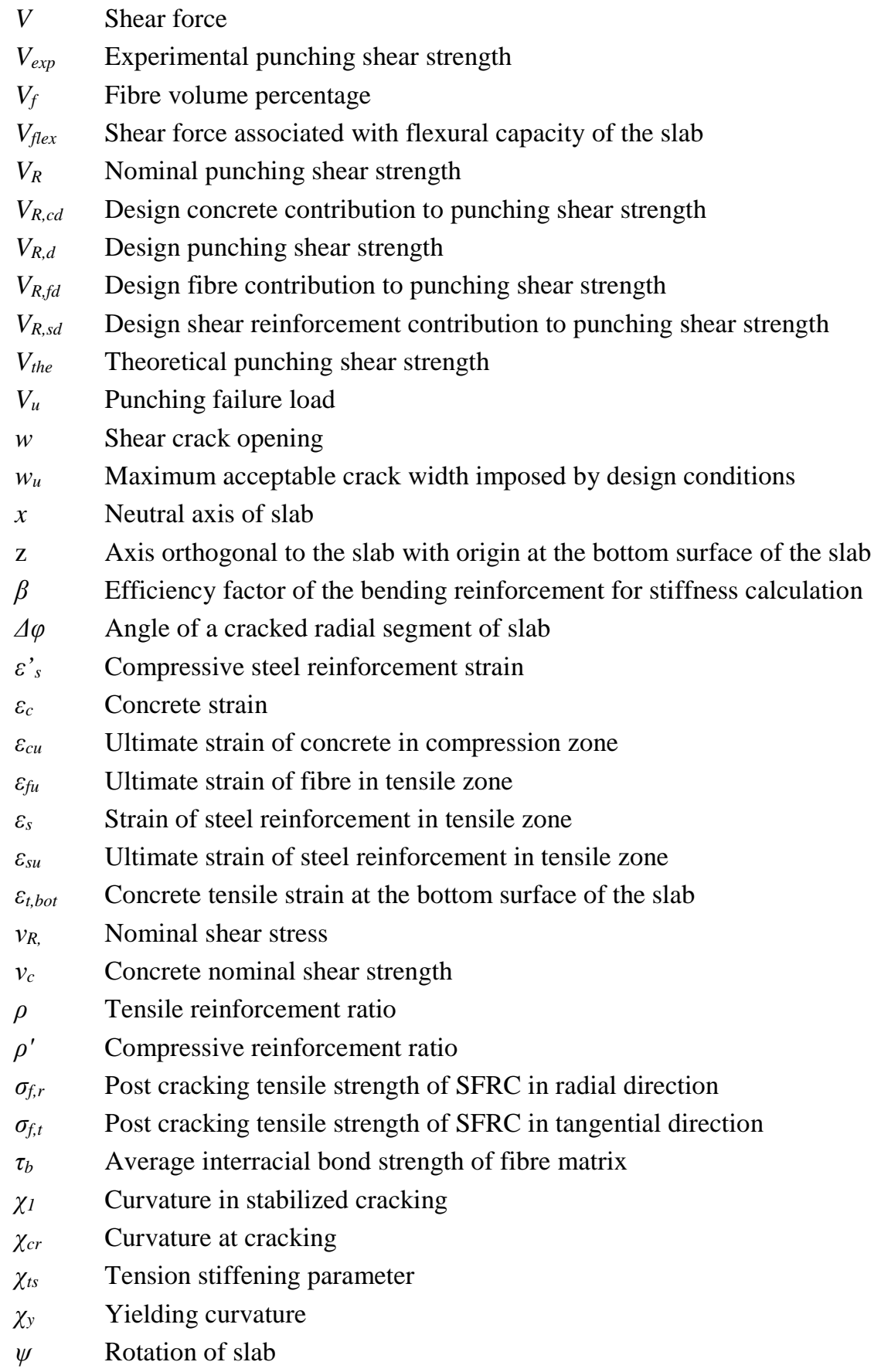




\section{APPENDIX: Theoretical Models}

\section{Narayanan and Darwish [8]:}

$V_{R}=\left(0.24 \cdot f_{s p}+16 \cdot \rho+0.41 \cdot \tau_{b} \cdot V_{f} \cdot a_{f} \cdot \frac{l_{f}}{d_{f}}\right) \cdot \xi_{s} \cdot u_{b} \cdot d \quad[\mathrm{MPa}, \mathrm{mm}]$

$u_{b}=\left(1-0.55 \cdot V_{f} \cdot a_{f} \cdot \frac{l_{f}}{d_{f}}\right) \cdot(4 \cdot e+3 \cdot \pi \cdot h) \quad[\mathrm{mm}]$

$a_{f}= \begin{cases}0.5 & \text { for round fibres } \\ 0.75 & \text { for crimped fibres } \\ 1.0 & \text { for duoform fibres }\end{cases}$

where $f_{s p}$ is the indirect cylinder tensile strength of fibre reinforced concrete (FRC), $\tau_{b}=4.15 \mathrm{MPa}$ is the average fibrematrix interfacial bond stress, $a_{f}$ is a factor depending of the fibre geometry, $\xi_{s}=(1.6-0.002 \cdot h)$ is an empirical factor depending of the slab's thickness, $h$, and $u_{b}$ is the critical perimeter.

\section{Shaaban and Gesund [29]:}

$V_{R}=0.6 \cdot\left(0.025 \cdot W_{f}+0.567\right) \cdot b_{0} \cdot d \cdot \sqrt{f_{c}} \quad[\mathrm{MPa}, \mathrm{mm}]$

$b_{0}=4 \cdot(e+d)$

$W_{f}=\frac{7850 \cdot V_{f}}{w_{c}}=\frac{7850 \cdot V_{f}}{2400}=3.27 \cdot V_{f}$

where $W_{f}$ is the weight fibre percentage, and $w_{c}$ is the specific weight of plain concrete.

\section{Harajli et al. [9]:}

$V_{R, f}=\left(0.033+0.075 \cdot V_{f}\right) \cdot b_{0} \cdot d \cdot \sqrt{f_{c}} \quad[\mathrm{MPa}, \mathrm{mm}]$

\section{Holanda [22]:}

$V_{R}=0.0035 \cdot d \cdot \sqrt{e \cdot d \cdot f_{c} \cdot \frac{\rho \cdot f_{s y}}{f_{c}} \cdot\left(170-\frac{\rho \cdot f_{s y}}{f_{c}}\right) \cdot\left(0.15 \cdot V_{f}+0.51\right) \cdot \sqrt{f_{c}}} \quad[\mathrm{MPa}, \mathrm{cm}, \%]$ 
$V_{R}=\sqrt[4]{\frac{400}{d}} \cdot \sqrt{0.263 \cdot \sqrt{f_{c}} \cdot\left[0.263 \cdot \sqrt{f_{c}}+\left(\alpha-\frac{\alpha^{2}}{3}\right) \cdot f^{\prime}{ }_{c f}\right]} \cdot A_{C}+0.105 \cdot\left(l_{f} / d_{f}\right) \cdot \sqrt{f_{c}} \cdot \beta \cdot A_{T} \cdot \cos \phi$

$\alpha \cdot \varepsilon_{c o f}=0.00196$

$\varepsilon_{c o f}=0.00079 \cdot V_{f} \cdot\left(\frac{l_{f}}{d_{f}}\right)+0.0041 \cdot\left(\frac{f^{\prime}{ }_{c f}}{f_{c}}\right)$

${f^{\prime}}^{\prime}=1.9 \cdot V_{f} \cdot\left(l_{f} / d_{f}\right) \cdot \beta+f_{c} \quad[\mathrm{MPa}]$

$A_{T}=\frac{\left(2 \cdot e_{1}+2 \cdot e_{2}+4 \cdot \cot \phi \cdot d\right) \cdot\left(d-c_{u}\right)}{\sin \phi}$

$A_{C}=\left(2 \cdot e_{1}+2 \cdot e_{2}+4 \cdot \cot \phi \cdot c_{u}\right) \cdot c_{u}$

$\beta= \begin{cases}1 & \text { for hooked } \text { or crimped steel fibres } \\ 2 / 3 & \text { for plain or round steel fibres with normal concrete } \\ 3 / 4 & \text { for plain or round steel fibres with lightweight concrete }\end{cases}$

where $f^{\prime}{ }_{c f}$ is the compressive strength of FRC, $f_{c}$ is the compressive strength of an equivalent concrete without fibres, $\beta$ accounts for the effect of fibre shape, $\phi=30^{\circ}$ is the average value of the angle formed by the punching failure crack with the slab's plan, $\alpha \varepsilon_{c o f}$ is the compressive strain at the extreme compression fiber of the cross section, and $\varepsilon_{c o f}$ is the compressive strain corresponding to the compressive strength of FRC, $c_{u}$ is the neutral axis position, $e_{1}$ and $e_{2}$ are the edges of the column's cross section and $A_{T}$ and $A_{C}$ are, respectively, the failure surfaces of tension and compression zones.

\section{Muttoni and Ruiz [10]:}

$V_{R}=V_{R, c}+V_{R, f}$

$V_{R, f}=\sigma_{t f}(w) \cdot A_{p}=\sigma_{t f}\left(\frac{\psi \cdot d}{6}\right) \cdot A_{p}$

$\sigma_{t f}(w)=\frac{1}{\pi} \cdot \arctan \left(\frac{w}{\alpha_{1} \cdot l_{f}}\right) \cdot\left(1-\frac{2 \cdot w}{l_{f}}\right)^{2} \cdot \frac{l_{f}}{d_{f}} \cdot V_{f} \cdot \tau_{b}$

$\alpha_{1}=\frac{d_{f}}{3.5 \cdot l_{f}}$

$\tau_{b}= \begin{cases}0.8 \cdot f_{c}^{0.5} & \text { for hooked ends fibres } \\ 0.6 \cdot f_{c}^{0.5} & \text { for crimped fibres } \\ 0.4 \cdot f_{c}^{0.5} & \text { for straight fibres }\end{cases}$

where $V_{R, c}$ is the concrete contribution to the punching shear resistance, $\sigma_{t f}$ is the post-cracking tensile strength of FRC for a crack width $w$, and $A_{p}$ is the horizontal projection of failure surface. 
7. Higashiyama et al. [31]:

$V_{R}=\beta_{d} \cdot \beta_{p} \cdot \beta_{r} \cdot\left(f_{p c d}+v_{b}\right) \cdot u_{p} \cdot d$

$f_{p c d}=0.2 \cdot \sqrt{f_{c}}<1.2 \mathrm{MPa}$

$\beta_{d}=\sqrt[4]{\frac{1000}{d}}<1.5$

$\beta_{p}=\sqrt[3]{100 \cdot \rho}<1.5$

$\beta_{r}=1+\frac{1}{1+0.25 \cdot(u / d)}$

$v_{b}=0.41 \cdot \tau_{b} \cdot F \quad$ with $\tau_{b}=4.15 \mathrm{MPa}$

$u_{p}=(u+\pi \cdot d) \cdot(1-K \cdot F) \quad$ with $\quad K=0.32$

$F=\frac{l_{f}}{d_{f}} \cdot V_{f} \cdot a_{f}$, with $V_{f}$ in percentage

$a_{f}= \begin{cases}0.5 & \text { for round fibres } \\ 0.75 & \text { for crimped fibres } \\ 1.0 & \text { for duoform fibres }\end{cases}$

where $u$ is the perimeter of the loaded area, $u_{p}$ is the perimeter of the critical section located at a distance of $d / 2$ from the contour of the loaded area. 


\section{LIST OF TABLE CAPTIONS}

Table 1. Modified version of the Demerit Points Classification (DPC)

Table 2. Prediction of $v_{\text {exp }}$ : classification of the proposals according to the modified version of the $D P C$

Table 3. Prediction of $V_{\text {exp }}$ : classification of the proposals according to the modified version of the $D P C$

Table 4. Performance of several models to predict $V_{\text {exp }}$ : classification of the models according to the modified version of the $D P C$

Table 1. Modified version of the Demerit Points Classification (DPC) [27]

\begin{tabular}{|c|c|c|}
\hline$\lambda=v_{\exp } / v_{\text {the }}$ & Classification & Penalty (PEN) \\
\hline$<0.50$ & Extremely Dangerous & 5 \\
\hline$[0.50-0.85[$ & Dangerous & 0 \\
\hline$[0.85-1.15[$ & Appropriate Safety & 1 \\
\hline$[1.15-2.00[$ & Conservative & 2 \\
\hline$\geq 2.00$ & Extremely Conservative & 0 \\
\hline
\end{tabular}


Table 2. Prediction of $v_{\text {exp }}$ : classification of the proposals according to the modified version of the DPC

\begin{tabular}{|c|c|c|}
\hline$\lambda=v_{\text {exp }} / v_{\text {the }}$ & $\mathrm{N}^{\circ}$ samples & PEN \\
\hline$<0.50$ & 0 & 15 \\
\hline$[0.50-0.85[$ & 3 & 0 \\
\hline$[0.85-1.15[$ & 28 & 9 \\
\hline$[1.15-2.00[$ & 9 & 0 \\
\hline$\geq 2.00$ & 0 & 24 \\
\hline Total PEN & 40 & 1.04 \\
\hline Average (AVG) & Statistical resume & \\
\hline STD & & \\
\hline COV (\%) & & 0.17 \\
\hline
\end{tabular}


Table 3. Prediction of $V_{\text {exp }}$ : classification of the proposals according to the modified version of the $D P C$

\begin{tabular}{|c|c|c|c|c|c|c|}
\hline Proposals & \multicolumn{2}{|c|}{ Refined } & \multicolumn{2}{|c|}{ Simple } & \multicolumn{2}{|c|}{ Balanced } \\
\hline$\lambda=V_{\text {exp }} / V_{\text {the }}$ & $\mathrm{N}^{\circ}$ samples & PEN & $\mathrm{N}^{\circ}$ samples & PEN & $\mathrm{N}^{\circ}$ samples & PEN \\
\hline$<0.50$ & 0 & 0 & 0 & 0 & 0 & 0 \\
\hline$[0.50-0.85[$ & 2 & 10 & 5 & 25 & 4 & 20 \\
\hline$[0.85-1.15[$ & 37 & 0 & 38 & 0 & 39 & 0 \\
\hline$[1.15-2.00[$ & 11 & 11 & 7 & 7 & 7 & 7 \\
\hline$\geq 2.00$ & 0 & 0 & 0 & 0 & 0 & 0 \\
\hline Total PEN & 50 & 21 & 50 & 32 & 50 & 27 \\
\hline \multicolumn{7}{|c|}{ Statistical resume } \\
\hline Proposal & \multicolumn{2}{|c|}{ Refined } & \multicolumn{2}{|c|}{ Simple } & \multicolumn{2}{|c|}{ Balanced } \\
\hline Average (AVG) & \multicolumn{2}{|c|}{1.04} & \multicolumn{2}{|c|}{1.00} & \multicolumn{2}{|c|}{1.01} \\
\hline STD & \multicolumn{2}{|c|}{0.13} & \multicolumn{2}{|c|}{0.13} & \multicolumn{2}{|c|}{0.13} \\
\hline $\mathrm{COV}(\%)$ & \multicolumn{2}{|c|}{12.72} & \multicolumn{2}{|c|}{13.22} & \multicolumn{2}{|c|}{12.74} \\
\hline
\end{tabular}


Table 4. Performance of several models to predict $V_{\text {exp }}$ : classification of the models according to the modified version of

\begin{tabular}{|c|c|c|c|c|c|c|c|c|c|c|}
\hline \multicolumn{2}{|c|}{$\lambda=V_{\text {exp }} / V_{\text {the }}$} & $<0.50$ & $\begin{array}{c}{[0.50-} \\
0.85[\end{array}$ & $\begin{array}{c}0.85- \\
1.15[\end{array}$ & $\begin{array}{l}{[1.15-} \\
2.00[\end{array}$ & $\geq 2.00$ & $\begin{array}{l}\text { Total } \\
\text { PEN }\end{array}$ & $\begin{array}{l}\text { Average } \\
\text { (AVG) }\end{array}$ & STD & $\begin{array}{c}\mathrm{COV} \\
(\%)\end{array}$ \\
\hline \multirow{2}{*}{ MOD1 } & $\mathrm{N}^{\circ}$ samples & 0 & 21 & 21 & 8 & 0 & 50 & \multirow{2}{*}{0.92} & \multirow{2}{*}{0.23} & \multirow{2}{*}{25.29} \\
\hline & PEN & 0 & 105 & 0 & 8 & 0 & 113 & & & \\
\hline \multirow{2}{*}{ MOD2 } & $\mathrm{N}^{\circ}$ samples & 0 & 2 & 18 & 29 & 1 & 50 & \multirow{2}{*}{1.24} & \multirow{2}{*}{0.26} & \multirow{2}{*}{20.89} \\
\hline & PEN & 0 & 10 & 0 & 29 & 2 & 41 & & & \\
\hline \multirow{2}{*}{ MOD3 } & $\mathrm{N}^{\circ}$ samples & 0 & 5 & 18 & 20 & 7 & 50 & \multirow{2}{*}{1.42} & \multirow{2}{*}{0.62} & \multirow{2}{*}{43.38} \\
\hline & PEN & 0 & 25 & 0 & 20 & 14 & 59 & & & \\
\hline \multirow{2}{*}{ MOD4 } & $\mathrm{N}^{\circ}$ samples & 0 & 0 & 8 & 42 & 0 & 50 & \multirow{2}{*}{1.32} & \multirow{2}{*}{0.20} & \multirow{2}{*}{15.47} \\
\hline & PEN & 0 & 0 & 0 & 42 & 0 & 42 & & & \\
\hline \multirow{2}{*}{ MOD5 } & $\mathrm{N}^{\circ}$ samples & 0 & 6 & 17 & 27 & 0 & 50 & \multirow{2}{*}{1.20} & \multirow{2}{*}{0.29} & \multirow{2}{*}{24.03} \\
\hline & PEN & 0 & 30 & 0 & 27 & 0 & 57 & & & \\
\hline \multirow{2}{*}{ MOD6 } & $\mathrm{N}^{\circ}$ samples & 0 & 6 & 37 & 7 & 0 & 50 & \multirow{2}{*}{0.99} & \multirow{2}{*}{0.13} & \multirow{2}{*}{13.26} \\
\hline & PEN & 0 & 30 & 0 & 7 & 0 & 37 & & & \\
\hline \multirow{2}{*}{ MOD7 } & $\mathrm{N}^{\circ}$ samples & 0 & 20 & 24 & 6 & 0 & 50 & \multirow{2}{*}{0.92} & \multirow{2}{*}{0.18} & \multirow{2}{*}{19.45} \\
\hline & PEN & 0 & 100 & 0 & 6 & 0 & 106 & & & \\
\hline \multirow{2}{*}{ Refined } & $\mathrm{N}^{\circ}$ samples & 0 & 2 & 37 & 11 & 0 & 50 & \multirow{2}{*}{1.04} & \multirow{2}{*}{0.13} & \multirow{2}{*}{12.72} \\
\hline & PEN & 0 & 10 & 0 & 11 & 0 & 21 & & & \\
\hline Simel & $\mathrm{N}^{\circ}$ samples & 0 & 5 & 38 & 7 & 0 & 50 & 100 & 012 & 1222 \\
\hline & PEN & 0 & 25 & 0 & 7 & 0 & 32 & 1.00 & 0.15 & 15.22 \\
\hline Dalanad & $\mathrm{N}^{\circ}$ samples & 0 & 4 & 39 & 7 & 0 & 50 & 101 & 012 & 1274 \\
\hline Daicancea & PEN & 0 & 20 & 0 & 7 & 0 & 27 & 1.01 & 0.15 & 12.14 \\
\hline
\end{tabular}

MOD1= Narayanan and Darwish [8]; MOD2= Shaaban and Gesund [29]; MOD3= Harajli et al. [9]; MOD4= Holanda [22]; MOD5= Choi et al. [30]; MOD6= Muttoni and Ruiz [10]; MOD7= Higashiyama et al. [31]. 


\section{LIST OF FIGURE CAPTIONS}

Figure 1. Column-slab connection: (a) Assumed crack pattern and reinforcement arrangement, (b) Slab configuration at ultimate condition.

Figure 2. Internal forces acting in a radial segment: (a) Stresses and resultant forces, (b) Bending moments (c) Free body diagram.

Figure 3. Transformation of a square slab (a) into an equivalent slab of circular geometry (b).

Figure 4. (a) $2 \mathrm{~L}$ and $4 \mathrm{~L}$ moment curvature $(m-\chi)$ diagrams, (b) $m-r$ diagram corresponding to $4 \mathrm{~L} m-\chi$ diagram.

Figure 5. Adopted approach to evaluate the ultimate bending moment, $m_{R}$ (adapted from the CEB-FIP Model Code $2010[13])$.

Figure 6. Hypotheses adopted to derive the simplified load-rotation formulation: (a) Free body diagram of a radial segment, (b) bilinear (2L) $m-r$ relationship.

Figure 7. Punching critical perimeter adopted for the evaluation of the punching resistance in column of: (a) circular, (b) square cross section.

Figure 8. Analysis of the results: (a) Predictive performance, (b) Safe $(\lambda \geq 1)$ and unsafe $(\lambda<1)$ percentage of slabs, and (c) Dispersion of the results.

Figure 9. Assessment of the predictive performance of the proposed punching failure criterion (Eq. (46)).

Figure 10. Experimental versus theoretical results in terms of the relationship between normalized load and slab's rotation for slab: (a) L6 [22], (b) A1 [3] and (c) P11F31 [28].

Figure 11. Performance in terms of predicting the punching failure load of the proposals: (a) Refined, (b) Simple, (c) Balanced; (d) Dispersion of the predictions.

Figure 12. Performance of several models to predict $V_{\text {exp: }}$ MOD1= Narayanan and Darwish [8]; MOD2= Shaaban and Gesund [29]; MOD3= Harajli et al. [9]; MOD4= Holanda [22]; MOD5= Choi et al. [30]; MOD6= Muttoni and Ruiz [10]; MOD7= Higashiyama et al. [31]; Refined; Simple; Balanced . 

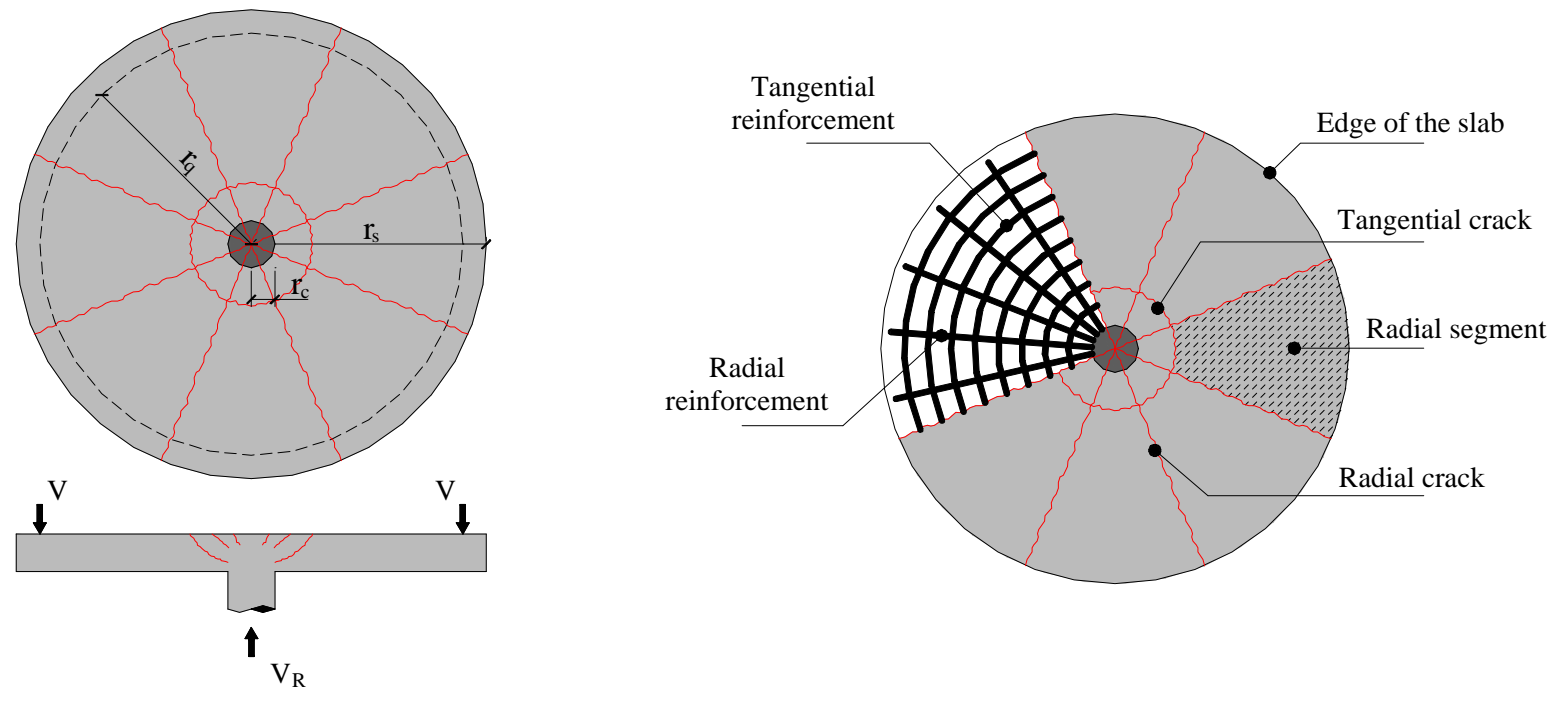

(a)

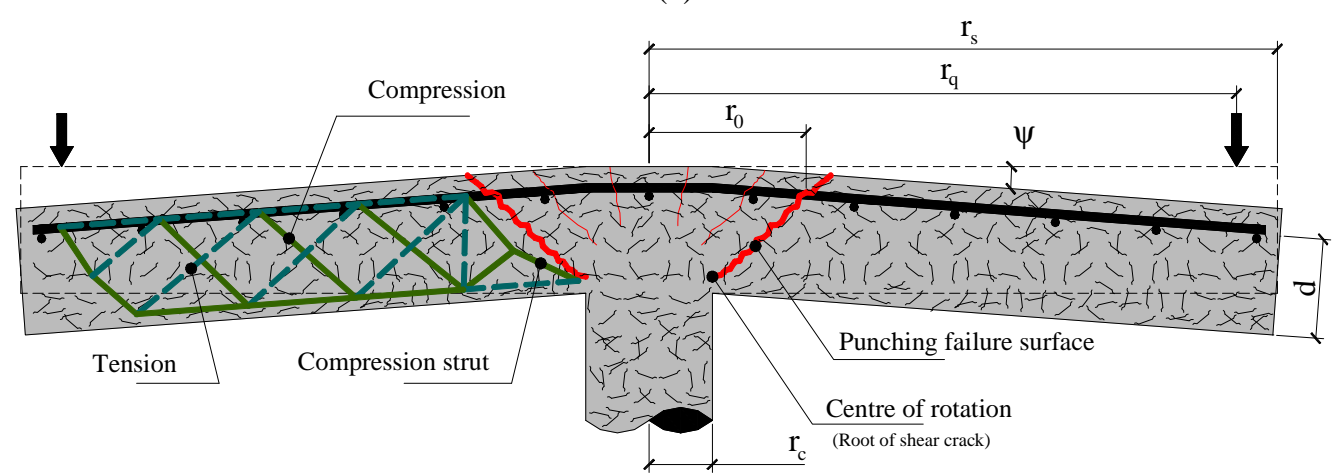

(b)

Figure 1. Column-slab connection: (a) Assumed crack pattern and reinforcement arrangement, (b) Slab configuration at ultimate condition. 


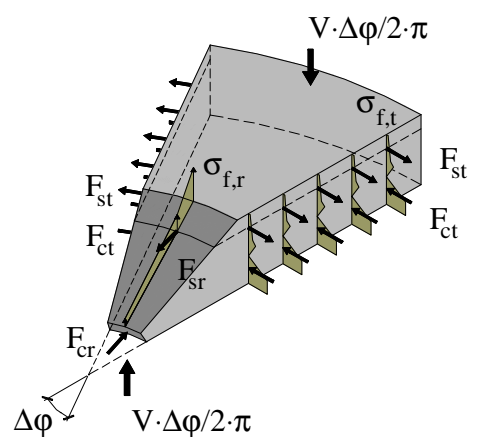

(a)

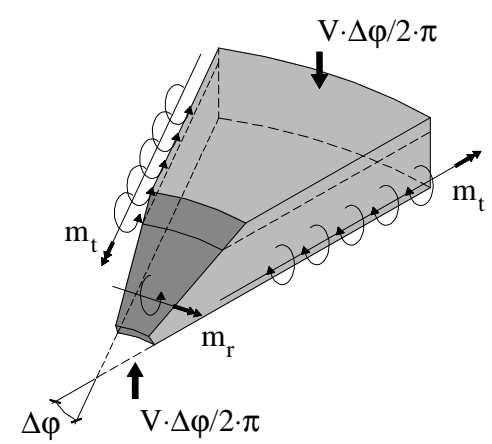

(b)

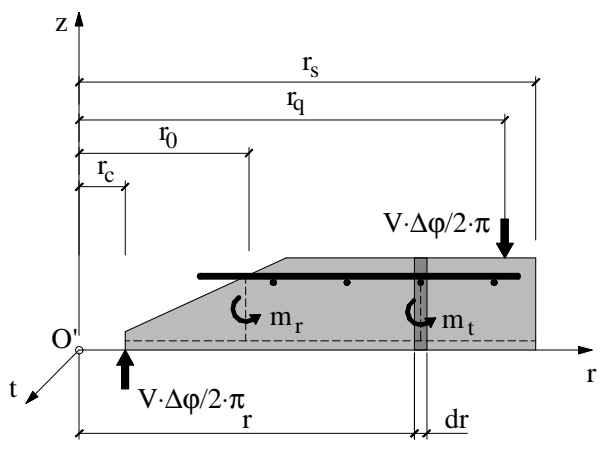

(c)

Figure 2. Internal forces acting in a radial segment: (a) Stresses and resultant forces, (b) Bending moments (c) Free body diagram. 


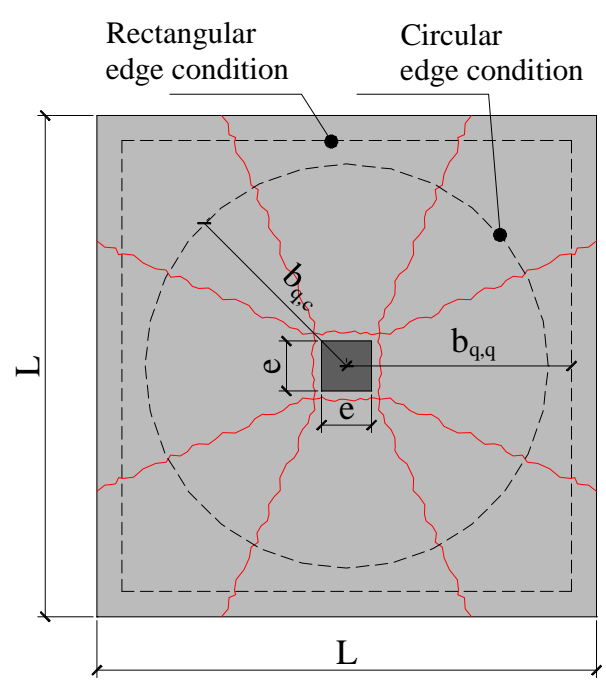

(a)

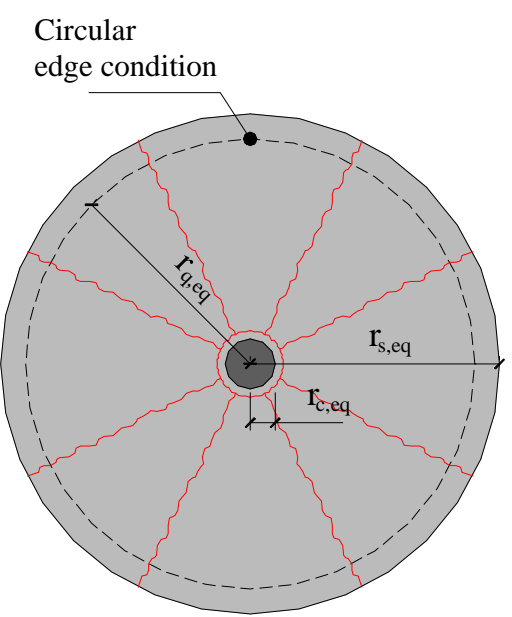

(b)

Figure 3. Transformation of a square slab (a) into an equivalent slab of circular geometry (b). 


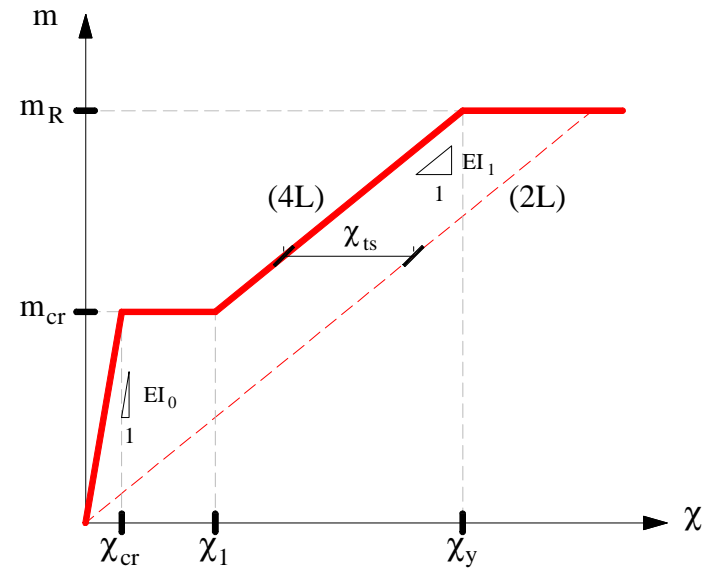

(a)

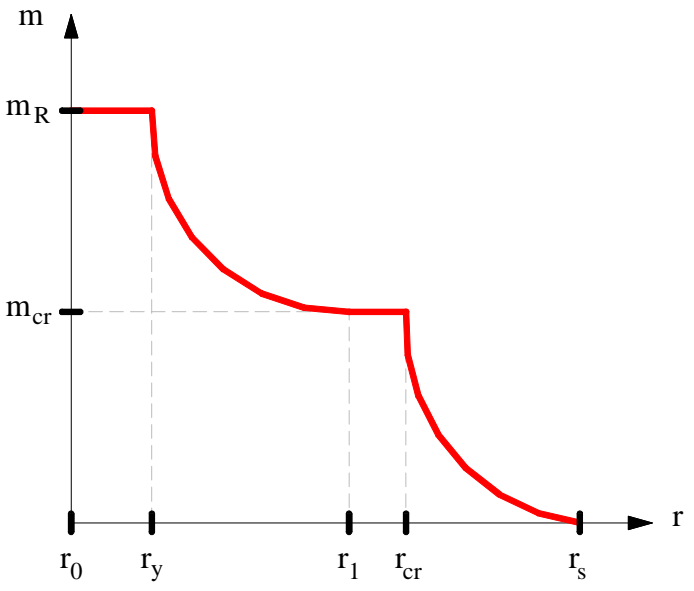

(b)

Figure 4. (a) $2 \mathrm{~L}$ and $4 \mathrm{~L}$ moment curvature ( $m-\chi)$ diagrams, (b) $m-r$ diagram corresponding to 4L $m-\chi$ diagram. 


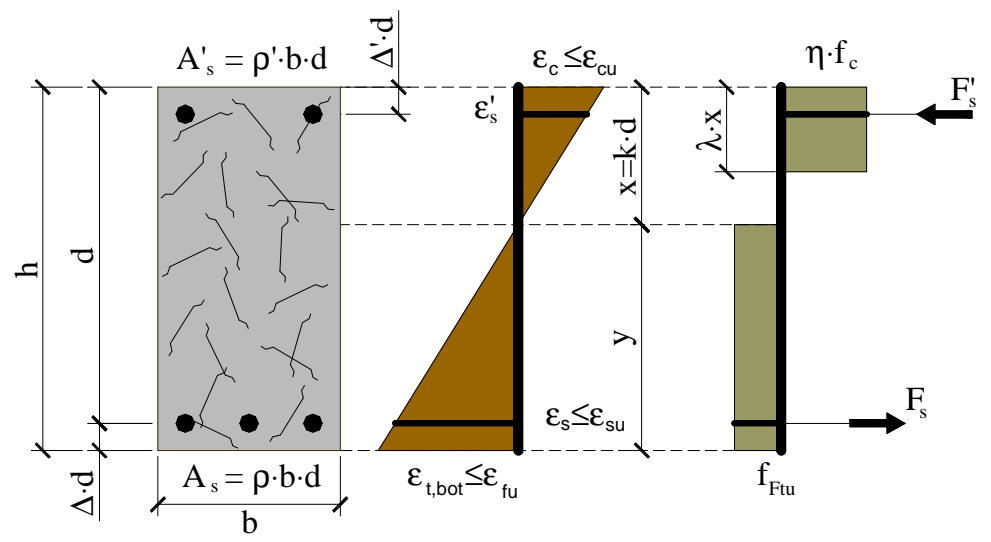

Figure 5. Adopted approach to evaluate the ultimate bending moment, $m_{R}$ (adapted from the CEB-FIP Model Code $2010[13])$. 


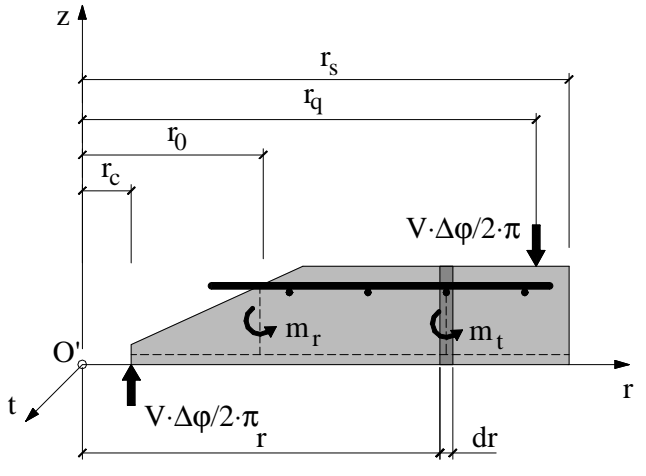

(a)

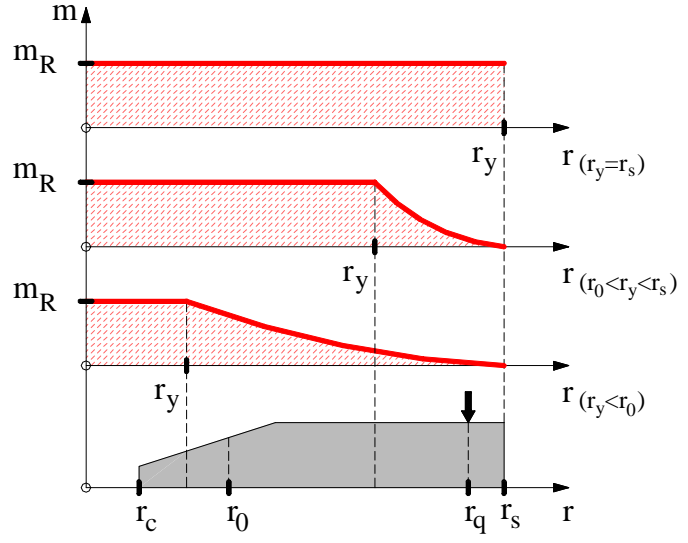

(b)

Figure 6. Hypotheses adopted to derive the simplified load-rotation formulation: (a) Free body diagram of a radial segment, (b) bilinear (2L) $m-r$ relationship. 


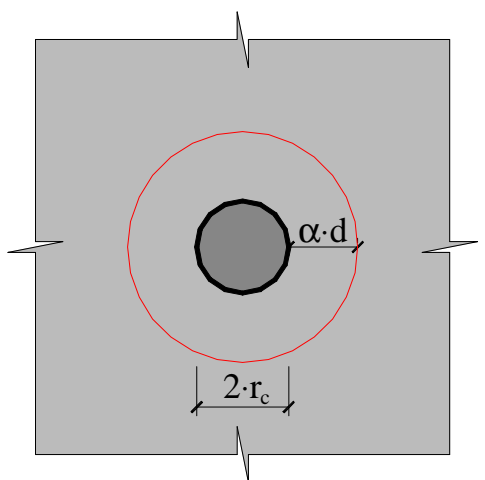

(a)

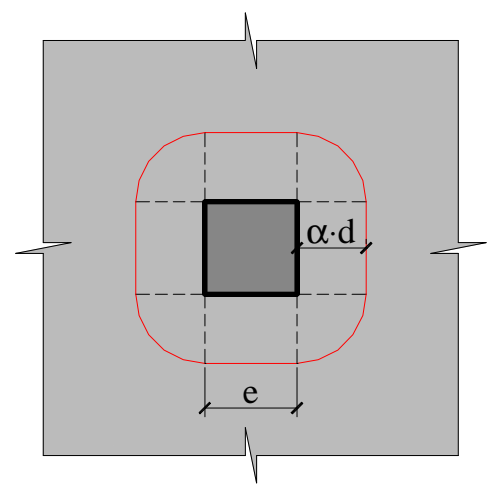

(b)

Figure 7. Punching critical perimeter adopted for the evaluation of the punching resistance in column of: (a) circular, (b) square cross section. 


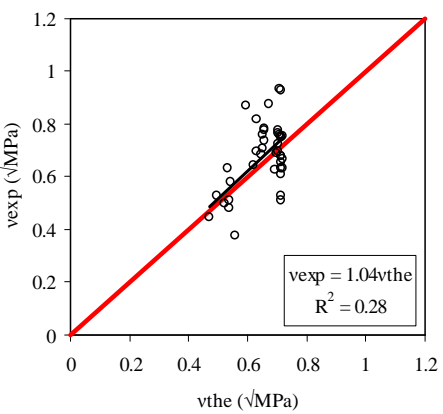

(a)

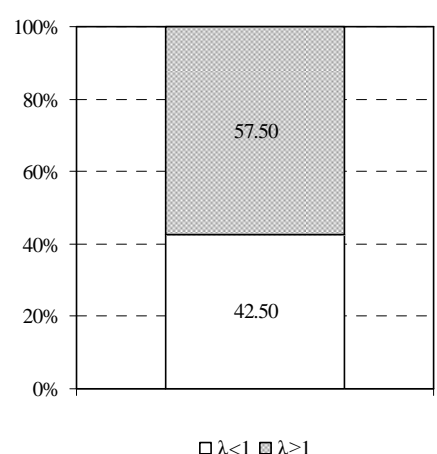

(b)

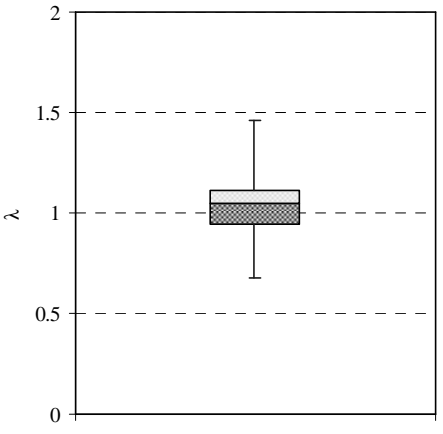

(c)

Figure 8. Analysis of the results: (a) Predictive performance, (b) Safe $(\lambda \geq 1)$ and unsafe $(\lambda<1)$ percentage of slabs, and (c) Dispersion of the results. 


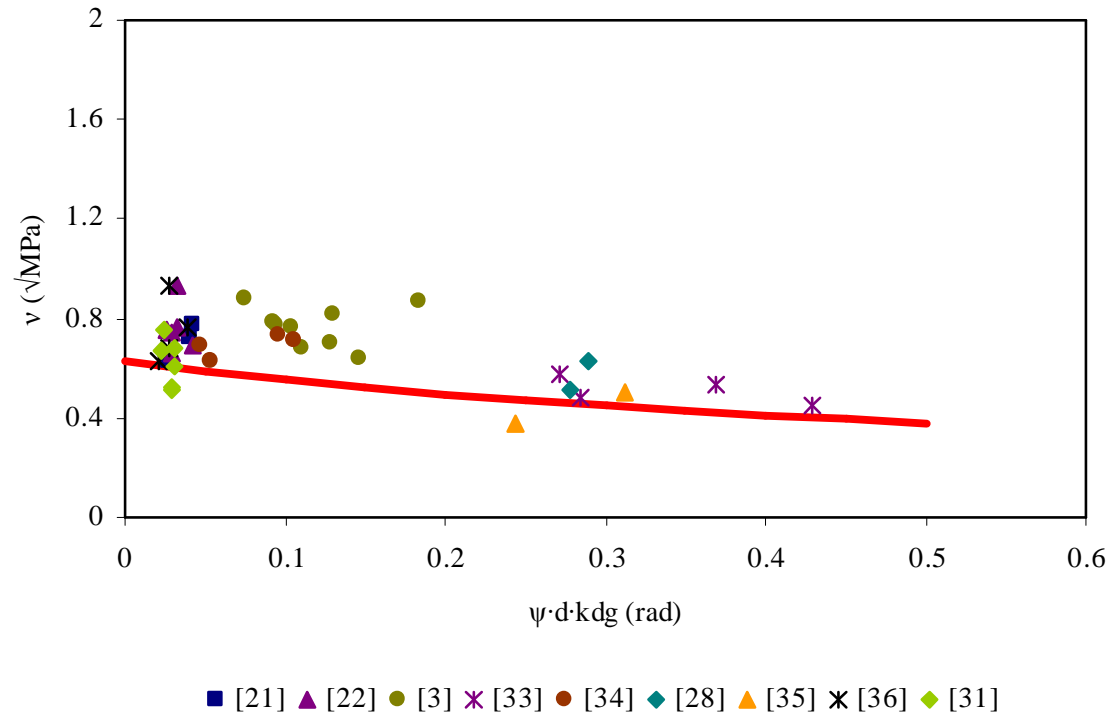

Figure 9. Assessment of the predictive performance of the proposed punching failure criterion (Eq. (46)). 


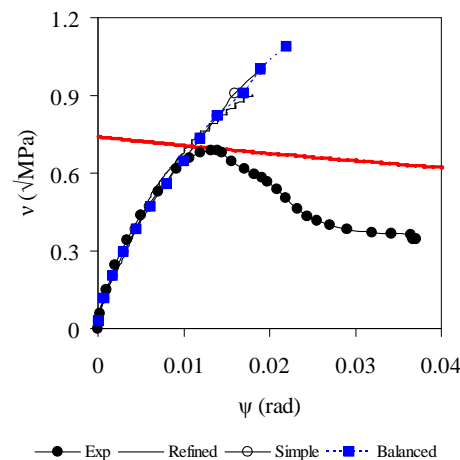

(a)

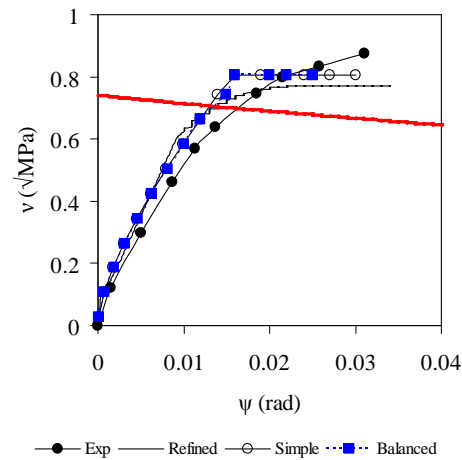

(b)

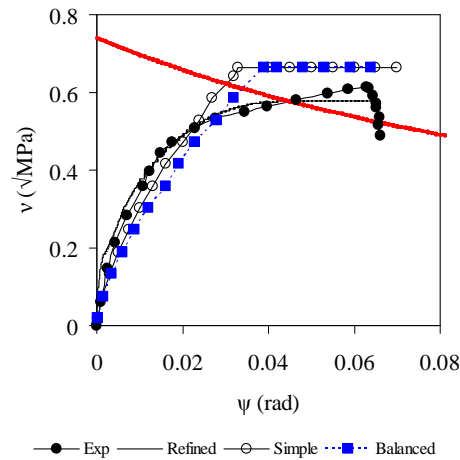

(c)

Figure 10. Experimental versus theoretical results in terms of the relationship between normalized load and slab's rotation for slab: (a) L6 [22], (b) A1 [3] and (c) P11F31 [28]. 


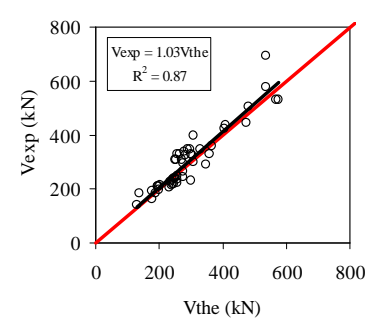

(a)

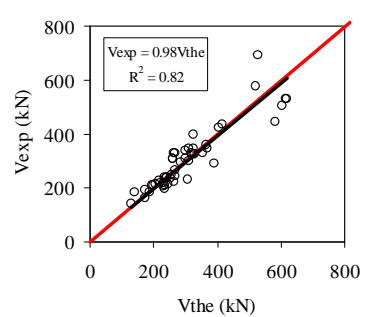

(b)

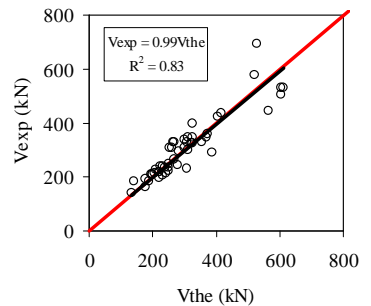

(c)

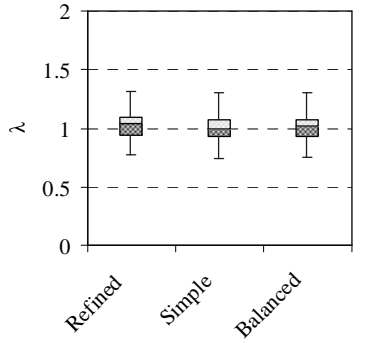

(d)

Figure 11. Performance in terms of predicting the punching failure load of the proposals: (a) Refined, (b) Simple, (c) Balanced; (d) Dispersion of the predictions. 


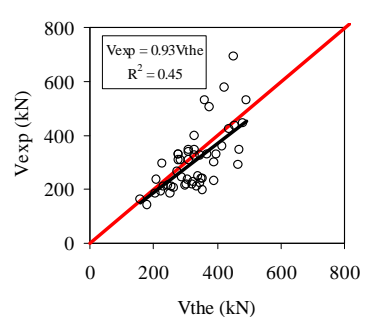

(a.1) MOD1

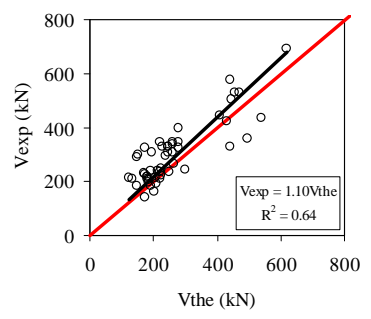

(a.5) MOD5

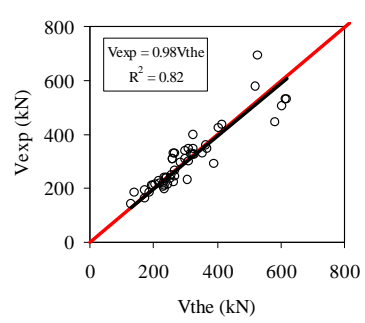

(a.9) Simple

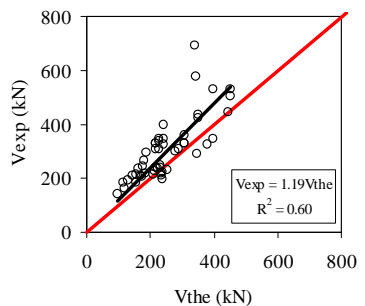

(a.2) MOD2

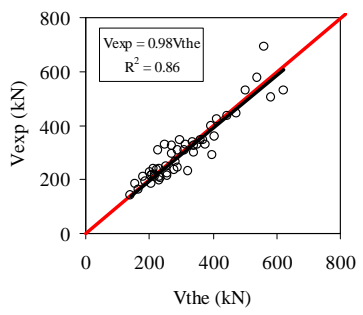

(a.6) MOD6

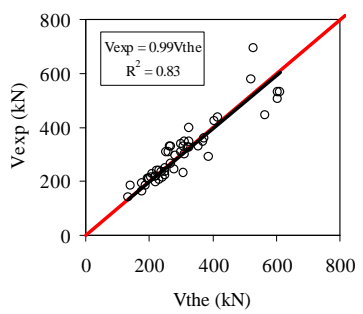

(a.10) Balanced

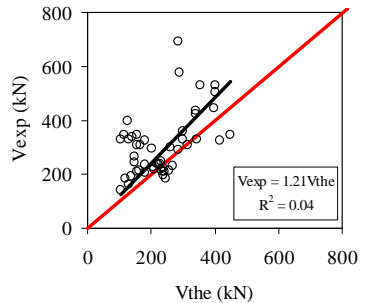

(a.3) MOD3

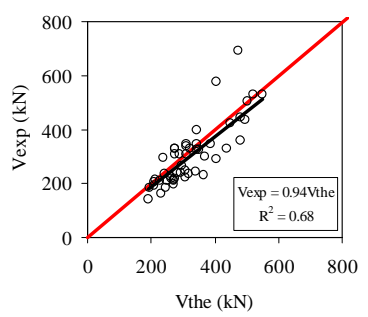

(a.7) MOD7

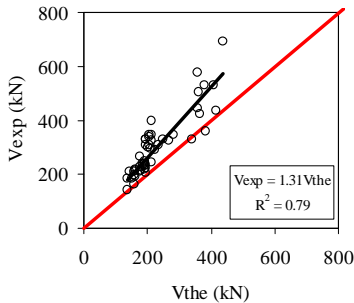

(a.4) MOD4

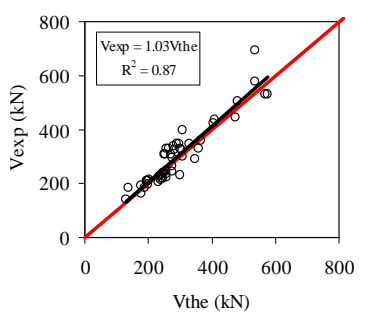

(a.8) Refined

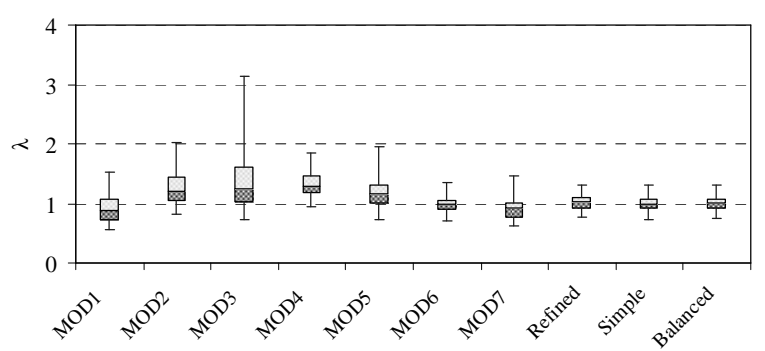

(b)

Figure 12. Performance of several models to predict $V_{\text {exp }}$ : MOD1= Narayanan and Darwish [8]; MOD2= Shaaban and Gesund [29]; MOD3= Harajli et al. [9]; MOD4= Holanda [22]; MOD5= Choi et al. [30]; MOD6= Muttoni and Ruiz [10]; MOD7= Higashiyama et al. [31]; Refined; Simple; Balanced. 